\title{
MASTER
}

\section{ON-LINE TESTS OF ORGANIC ADDITIVES FOR THE INHIBITION OF THE PRECIPITATION OF SILICA FROM HYPERSALINE GEOTHERMAL BRINE IV. FINAL TESTS OF CANDIDATE ADDITIVES}

J. E. Harrar

F. E. Locke

C. H. Otto, Jr.

L. E. Lorensen

W. P. Frey

E. 0. Sne11

This is an informal report intended primarily for internal or limited external distribution. The opinions and condusions stated are those of the author and may or may not be those of the Laboratory.

Work performed under the auspices of the U.S. Department of Energy by the Lawrence Livermore Laboratory under Contract W-7405-Eng-48. 


\section{DISCLAIMER}

This report was prepared as an account of work sponsored by an agency of the United States Government. Neither the United States Government nor any agency Thereof, nor any of their employees, makes any warranty, express or implied, or assumes any legal liability or responsibility for the accuracy, completeness, or usefulness of any information, apparatus, product, or process disclosed, or represents that its use would not infringe privately owned rights. Reference herein to any specific commercial product, process, or service by trade name, trademark, manufacturer, or otherwise does not necessarily constitute or imply its endorsement, recommendation, or favoring by the United States Government or any agency thereof. The views and opinions of authors expressed herein do not necessarily state or reflect those of the United States Government or any agency thereof. 


\section{DISCLAIMER}

Portions of this document may be illegible in electronic image products. Images are produced from the best available original document. 


\section{ON-LINE TESTS OF ORGANIC ADDITIVES FOR THE INHIBITION OF THE PRECIPITATION OF SILICA FROM HYPERSALINE GEOTHERMAL BRINE IV. FINAL TESTS OF CANDIDATE ADDITIVES}

J. E. Harrar, F. E. Locke, C. H. Otto, Jr,, L. E. Lorensen, W. P. Frey, and E. O. Snell

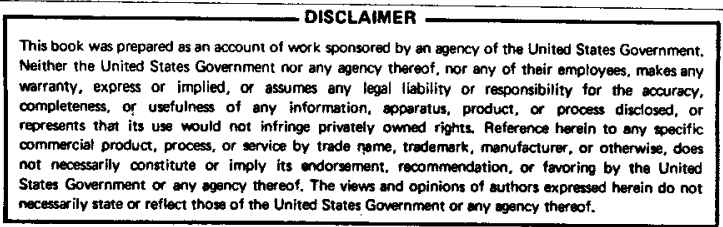


Abstract. ...................

Introduction. . . . . . . . . . . . . 2

Compounds Tested. . . . . . . . . . 5

Experimental Techniques . ........... 10

Brine Characteristics ............. 10

Results of Precipitation Tests. . . . . . . . . 12

Comments on the Mechanism of Inhibition of Silica

Precipitation and Scaling ............ 17

Results of Additional Precipitation Tests during

Scaling Rate Measurements ............ 21

Electrochemical Corrosion Rate Measurements . . . 25

Results of Scaling Rate Measurements. . . . . . 29

Surmary, Recommendations, and Conclusions . . . . . 33

Acknowledgments ................... 44

References ................. 45 


\section{Abstract}

The Lawrence Livermore Laboratory Brine Treatment Test System at Niland, Imperial Valley, California, has been used to evaluate a number of cationic polymers and surfactants as scale control agents. An initial group of compounds was narrowed to four on the basis of their activity as silica precipitation inhibitors. Three of these and certain combinations of compounds were then given a $40-h$ test to determine their effectiveness in retarding scales formed at 220,125 , and $90^{\circ} \mathrm{C}$. The best single compound was Corcat P-18 (Cordova Chemical Co. polyethylene imine, $M . W . \approx 1800$ ). It had no effect on the scale at $220^{\circ} \mathrm{C}$, but it reduced the scales at 125 and $90^{\circ} \mathrm{C}$ by factors of 4 and 18, respectively, and it also has activity as a corrosion inhibitor. Other promising compounds are $\mathrm{PAE} \cdot \mathrm{HC}$ [ [Dynapol poly (aminoethylene, HCl salt)], which also somewhat reduces the $220^{\circ} \mathrm{C}$ scale; Ethoquad $18 / 25$ [Armak methy] polyoxyethylene(15) octadecylammonium chloride]; and Mirapol A-15 (a Miranol Chemical polydiquaternary compound). The best additive formulation for the brines of the Salton Sea Geothermal Field appears to be a mixture of one of these silica precipitation inhibitors with a small amount of hydrochloric acjd and a phosphonate crystalline deposit inhibitor. In this report of our final test series, we present speculations as to the mechanism of inhibition of silica precipitation and recommendations for further testing of these additives. 
This report presents further resuits of our field test program to evaluate specific organic chemical compounds as additives for the abatement of scales formed from the brines of the Salton Sea Geothermal Field. References 1 to 3 are the previous detailed reports of results in this series; Reference 4 is a brief sumary of progress in FY1979. A final report of our tests of proprietary scale-control additives is also available. 5

Among all of the various compounds that we have tested, two general classes of substances appear to be the most effective in inhibiting the precipitation of silica from the hypersaline brine. In one group are compounds containing $\mathrm{large}$ amounts of the oxyethylene moiety, $-\mathrm{CH}_{2} \mathrm{CH}_{2} \mathrm{O}$-, and the other group comprises various nitrogen-containing compounds that behave in a cationic fashion in solution. In inhibiting the precipitation, these compounds probably function by the mechanism of steric colloidal stabilization, i.e., they adsorb on the sub-micron particles of silica to prevent their aggregation and flocculation.

Most recently, we have focussed our attention on the nitrogen-containing compounds because the polyoxyethylenes have appeared to be limited in high temperature solulbility. ${ }^{2,3}$ Among the cationic-functioning, nitrogencontaining substances, three types of compounds have emerged as the most potent inhibitors: quaternary ammonium compounds, polyethylene imines, and polyaminoethylene in the form of the hydrochloride salt. ${ }^{3}$ One of the quaternary ammonium compouns, Ethoquad 18/25, was subjected to a scale inhibition test evaluation and found to be moderately effective. This material is manufactured by the Armak Company and is methylpolyoxyethylene(15) octadecylammonium chloride. Its high activity toward silica was thought to be due to both the 15-mole content of oxyethylene and the strong cationic character. 
Ethoquad $18 / 25$ was tested alone at a level of $25 \mathrm{ppm}$, and at $20 \mathrm{ppm}$ in combination with the calcite-scale inhibitor, Dequest 2060 (Monsanto Chemical Company) at $5 \mathrm{ppm}$. The best result was obtained with the combination, which effected an $80 \%$ reduction in the rate of formation of scale at $90^{\circ} \mathrm{C}$. However, there was only a marginal degree of reduction of the scale at $125^{\circ} \mathrm{C}$ (barely larger than the experimental uncertainty), and no improvement at $210^{\circ} \mathrm{C}$. These results represented further progress in finding a viable organic antiscalant, but to be really useful, a candidate additive must also show significant activity toward the intermediate-temperature scale. In the strongest brines ( $2.5 \mathrm{Mol} / 1$ chloride), the $125^{\circ} \mathrm{C}$ scaling rate is $21 \mathrm{mil} / \mathrm{h}$ (vs. $0.1 \mathrm{mil} / \mathrm{h}$ at $210^{\circ} \mathrm{C}$ and $5 \mathrm{mi} / \mathrm{h}$ at $90^{\circ} \mathrm{C}$ ), and this would be intolerable in an operating plant even if the $90^{\circ} \mathrm{C}$ scaling were absent.

Thus in our continued testing, we hoped to find a compound that would be still more effective in reducing the low temperature scale, but more important ly one that would retard the growth of the intermediate-temperature scale. The $125^{\circ} \mathrm{C}$ point in the system is especially difficult because the driving forces for silica precipitation - the degree of supersaturation and the temperature - are both high.

In this final series of experiments of the scale-control project, we first planned to screen a new group of compounds selected from the classes of known activity. In this group were the following:

- A series of quaternary ammonium compounds, obtained from Armak, to be compared especially with the ir Ethoquad 18/25,

- A series of polyethylene imines, obtained from Cordova Chemical

- Company, having different molecular weights and derivatized with certain other functional groups,

- Three polyaminoethylene hydrochloride salts, obtained from Dynapol, Inc., including the PAE.HCl tested previous $1 y, 3$ and

- A group of miscellaneous quaternary ammonium and polyamine-type compounds having certain features not previously tested. 
These compounds were first evaluated by means of our "standard" precipitation test, ${ }^{6}$ in which the additive is injected into the brine-treatment test system at $210^{\circ} \mathrm{C}$, samples of effluent brine are collected at $125^{\circ} \mathrm{C}$, and then the kinetics of silica precipitation are observed at $90^{\circ}$.

In addition to testing single compounds shown to be good inhibitors in the precipitation test, we planned to conduct scaling tests of combinations of compounds with complementary functions which, it was hoped, would lead to significant retardation of scale. For example, it was speculated that a reason why little, if any, scale abatement had been observed at $125^{\circ} \mathrm{C}$ on treatment with organic compounds is that much of this scale forms directly from monomeric silica rather than capture of particulate silica. If this is true, scale deposition could not be inhibited by the mechanism of steric stabilization. Scanning electron micrographs of the scale are being obtained to shed some light on this question. Meanwhile, it has appeared that adjustment of the $\mathrm{pH}$ of the brine to alter the rate of polymerization of silica, coupled with the addition of an organic additive to stabilize the colloidal silica, could be an effective approach to scale control.

The Ethoquad 18/25-Dequest 2060 mixture tested previously $y^{3}$ is an example of a synergistic combination of additives. Dequest 2060 (diethylenetriamine pentamethylene phosphonic acid) inhibits calcium carbonate deposition and has been shown to be effective in geothermal brine. ${ }^{7}$ The scale of the Salton Sea Geothermal Field contains $<1 \% \mathrm{CaCO}_{3}$; however, it has been conjectured ${ }^{8}$ that the precipitation of small amounts of $\mathrm{CaCO}_{3}$ may enhance the nucleation of silica. The beneficial effect observed for the combination of the silica and $\mathrm{CaCO}_{3}$ inhibitors may be explained on this basis. Two other combinations to be tested were (1) a mixture of a silica precipitation inhibitor and a filming amine corrosion inhibitor, and (2) a mixture of a cationic silica precipitation inhibitor and an anionic surfactant that is reactive toward the cationic substance, to examine the possibility of forming a more strongly adsorbed film on the silica particles. 
Compounds Tested

Five compounds were obtained from the Armak Company for evaluation. Three of these were variations of the following structure:

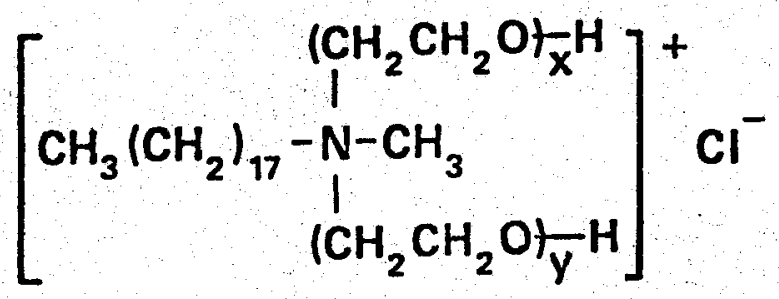

In the compound previously tested, ${ }^{2,3}$ Ethoquad $18 / 25, x+y=15$, with the polyoxyethylene chains being about equal length. Another compound was Ethoquad HT-60MS, which has 50 molecules of oxyethylene substitution. Also tested was the homolog Arquad 18/50, which has no oxyethylene; in this compound there is a methyl group in place of each $-\mathrm{CH}_{2} \mathrm{CH}_{2} \mathrm{O}$ - chain in the structure above. These three compounds afforded a test of the effect of the amount of oxyethylene on the activity of these quaternary ammonium compounds as silica precipitation inhibitors. Previous testing ${ }^{2}$ suggested a desirable trend toward greater oxyethylene substitution, but those results involved more diverse substances from different manufacturers.

Also tested was Armak's Duoquad T-50. This compound has two quaternary ammonium groups per molecule and is characterized by the structure<smiles>[2H]N(C)CCN(C)C</smiles> 
where the $R$ group represents an alkyl chain of 14 to 18 carbon atoms derived from tallow. Because part of the activity of the cationic substances toward silica may be due to an attraction to the negatively-charged silica particles, we thought that a dipositive cation, or "diquat," might be even more potent. Two other diquats, to be described below, were also tested.

The fifth Armak compound examined was Duomac $T$, the acetic acid salt of N-tallow-1,3-diami nopropane:

$$
\frac{\mathrm{HOAC}}{\mathrm{R}-\mathrm{H}_{\mathrm{H}}+\mathrm{CH}_{2} \mathrm{~T}_{3}} \mathrm{NH}_{2} \cdot \mathrm{HOAC}
$$

It was not expected to inhibit the precipitation of silica because only ethoxylated amines have exhibited such activity. ${ }^{1,2}$ Rather, this compound was selected for its activity as a corrosion inhibitor. This has been demonstrated in other applications, where it is strongly attracted to steel surfaces to form an inhibiting film. In our experiments, it was eventually evaluated in a scaling test with Ethoquad 18/25.

The polyethylene imines are another type of compound that had shown promise in earlier investigations. ${ }^{2}$. They have the structure

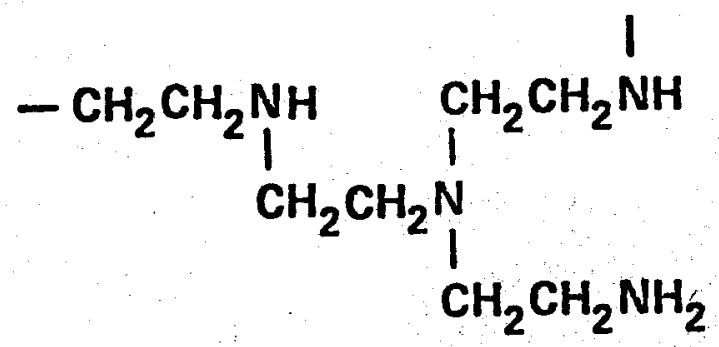


and are manufactured by the Cordova Chemical Company. As indicated in the structure shown, extensive branching during polymerization leads to molecules in which the nitrogens are approximately one-third primary, one-third secondary, and one-third tertiary. Previously tested were the Corcat P-145 and Corcat P-200, which have molecular weights (M.W.) of $\sim 40,000$ and 220,000 , respectively. Since the Corcat $P-200$ was the most effective, two lower molecular weight compounds were acquired for testing: Corcat $P-100$ (M.W. $=10,000)$ and Corcat P-18 (M.W. $=1800)$

In addition, because it was of interest to learn whether modification of the basic polyethylene imine could increase its activity as a precipitation inhibitor, three derivatized versions of the Corcat $P-100$ were obtained as special preparations. One was quaternized with methyl chloride; the quaternized compound, it was hoped, would have an enhanced attraction to the silica. This quaternized $P-100$ was analyzed after preparation and found to have $70 \%$ of its nitrogens in the quaternary form.

A second derivative was made by reacting chloroacetic acid with $P-100$. polyethylene imine to produce the following substitutions:

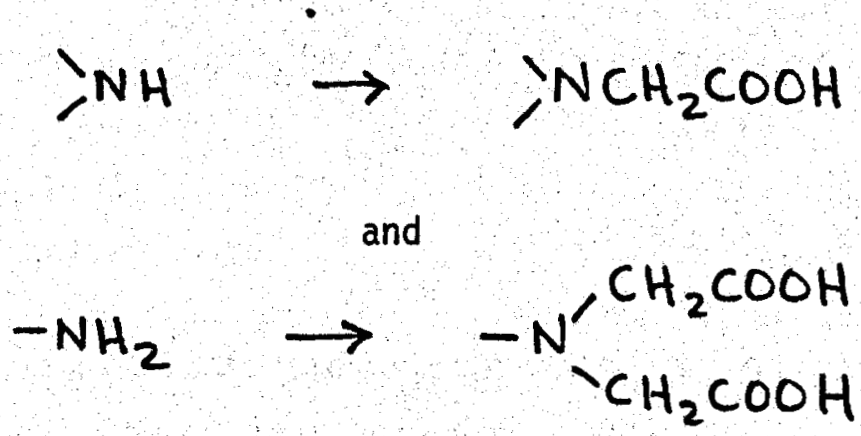

The tertiary nitrogens were left unchanged. In this manner, 20.8 mole of modifier was added per mole of ethylene imine in the overall molecule, and an anionic character was conferred. The resulting molecule, still having the tertiary nitrogens, thus was amphoteric.

The third P-100 modification was a glycidol derivative involving the following substitutions: 


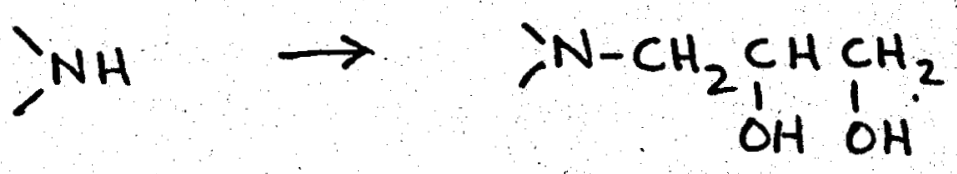

and

$$
\left.-\mathrm{NH}_{2} \rightarrow-\mathrm{N}-\mathrm{CH}_{2} \mathrm{CH}_{\mathrm{OH}}^{\mathrm{CH}} \mathrm{CH}_{2}\right)_{2}
$$

This reaction also did not affect the tertiary nitrogens, and $\sim 1.0$ mole of the modifier was reacted per mole of ethylene imine in the overall molecule. This derivative was selected with the thought that the hydroxyl groups might confer additional water solubility and possibly the type of bonding to silica that is exhibited by the polyoxyethylenes.

The third particular group of compounds evaluated were those marketed by Dynapol under the trade name PAE.HCI, 9 and having the general structure

$$
+\left.\right|_{\mathrm{NH}_{2}} ^{\mathrm{CH}_{2}} \mathrm{CH}_{2} \mathrm{HCl}_{\mathrm{n}}
$$

or<smiles>CCCC[NH3+]</smiles>

One of these compounds, in which the peak average molecular weight was 120,000 , was tested previous $1 y^{3}$ and found to be the most powerful silica precipitation inhibitor yet discovered -- much stronger than Ethoquad 18/25 in the rapidly scaling brine of the June test series. However, it was not evaluated in a scaling test, and it was of interest to determine whether other molecular weights of this polymer would have greater potency. For the present evaluation, a second sample of the PAE.HCl (M.W. $=120,000)$, and a sample of PAE $\cdot H C l$ (M.W. $=25,000)$ were obtained. Also, because the PAE $\mathrm{HCl}$ as 
normally produced has a rather high cost $\left(\$ 8 \pm 2 / 1 \mathrm{~b}\right.$ for $10^{6} \mathrm{lb} /$ year $)$, a third sample was supplied in which the PAE.HCl of M.W. $=25,000$ was synthesized by a less expensive (Hofmann) route. The PAE.HCl chemicals are manufactured by a process in which the polymer hydrochloride salt is obtained in a hydrochloric acid solution, which is then partially neutralized before shipment. In the un-neutralized form, there are 23 equivalents of $\mathrm{HCl}$ for each amino equivalent; in the form that we tested, the solution had been neutralized to a $\mathrm{pH}$ of 4.0 .

Several other compounds that are related in various ways to the substances previously found to be good precipitation inhibitors were also acquired for testing. One of these was Mirapol A-15, manufactured by the Miranol Chemical Company, which has the following structure:

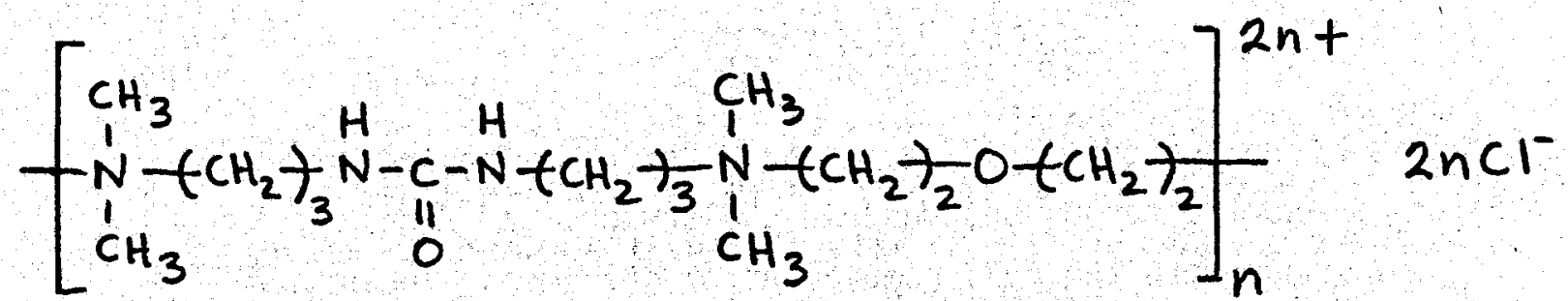

where $n \approx 6$.

This compound is both a diquat and a small polymer of M.W. $=2200$. We obtained this compound for testing as an inhibitor, both alone, and together with an anionic surfactant with which it is known to form a complex ${ }^{10}$ : sodium lauryl ether sulfate (Cyclo Chemicals "Cycloryl NA").

Another diquat tested is Schercoquat DAB-90 (Scher Chemicals, Inc.) having the following structure:<smiles>[R]C(=O)NCCN(C)Cc1ccccc1</smiles> 
This compound is synthesized from isomeric "dimer acid"; the R group in the structure denotes the hydrocarbon portion of a dimerized, unsaturated fatty acid containing 236 carbons.

In our very first off-line tests of compounds for the inhibition of silica precipitation, we found that a technical protein had no effect. To learn whether quaternizing such a material would render it active, we obtained a quaternized protein, Crotein BTA, from Croda, Inc. This compound has a molecular weight of $\sim 5000$ and only its terminal amino groups ( $10 \%$ of the molecule) are quaternized.

The last two compounds tested were polymeric tertiary amines obtained from American Cyanamid Company. They are designated RC-412 and RC-413 and have molecular weights of 210,000 and 230,000 , respectively.

\section{Experimental Techniques}

The additives were tested with Magmamax No. 1 brine using the apparatus shown in Figure 1 and the techniques described el sewhere. ${ }^{4,5}$ Scaling rate measurements were made with the full complement of specimens, including sections of $\frac{1}{2}$ - and $\frac{1}{4}-i n$. tubing placed at the outlet of the delay stage to obtain data on scaling rates at $90^{\circ} \mathrm{C}$. Measurements of the scaling rates on mild steel coupons were performed by placement of the coupons on 2-in. pipe plugs inserted near the Petrolite probes, instead of in the flanges of the 1-in. pipe spools as was done previously. ${ }^{5}$ Precipitation tests were carried out on the effluent brine samples collected at the atmospheric flash temperature of $105^{\circ} \mathrm{C}$ and incubated anaerobically at $90^{\circ} \mathrm{C} .6$

\section{Brine Characteristics}

The final test series was conducted during late october and early November, 1979, while the Magma Power Company was also flowing the we11. The total well flow rate was $100-150 \mathrm{gpm}$, compared to $\sim 50 \mathrm{gpm}$ when $L L L$ is operating alone. The result was a brine of intermediate salinity, 


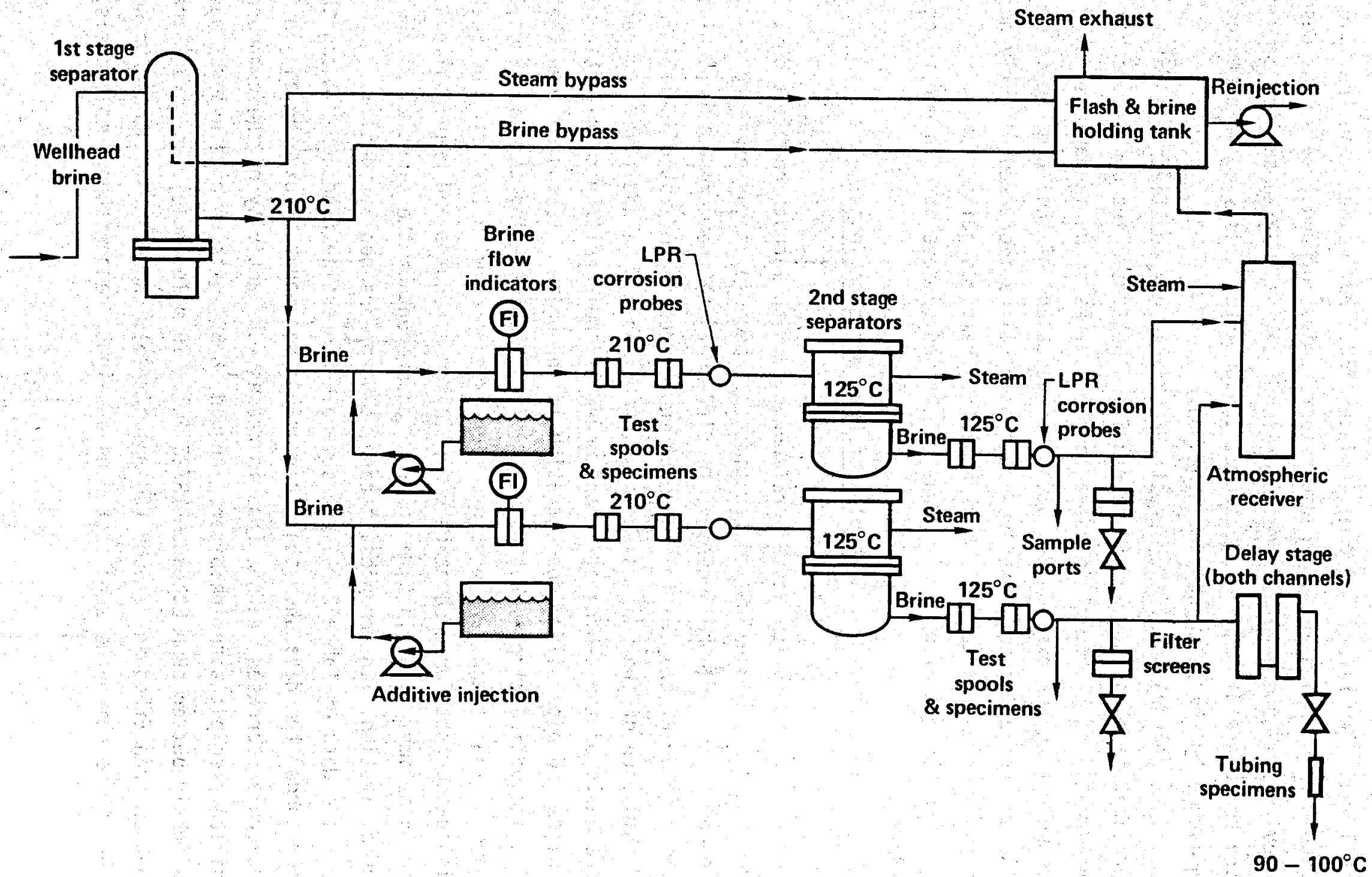


4.0-4.2 Mol/l chloride, which was comparable to the conditions existing at full well flow rate $(\sim 600 \mathrm{gpm})$ in late $1978,,^{5}$ but weaker than the $\sim 4.5 \mathrm{Mol} / 1$ condition existing in the previous test series ${ }^{3}$ of June, 1979. As described previously, ${ }^{3}$ the rate of precipitation of silica and the scaling tendency of the brine are directly proportional to the total dissolved salt content, as measured by the chloride concentration.

Intercomparison of the effects of the various additives via the precipitation and scaling tests requires that the brine conditions be reasonably constant. This was accomplished, as shown in Table 1, by coordinating our experiments with the operations of the Magma Power Company. The concentrations of dissolved salts and silica increased slightly during the first two days of testing, but thereafter remained quite stable.

The concentration of iron was determined on November 4 th and found to be $182 \mathrm{mg} / \mathrm{kg}$.

\section{Results of Precipitation Tests}

The precipitation tests were conducted with incubation times of 1 and $2 h$, rather than the usual $\frac{1}{2}$ and $1-h$ times, 1,3 because it was expected that the longer times would be necessary to differentiate the more potent inhibitors. The results of the initial round of measurements are listed in Table 2. Within each of the four categories in the Table, the additives are ranked, on the basis of the 1-h data, in the order of their ability to maintain a low solids and high silica concentration in the brine. It can be seen that the 2-h incubation time is not as useful in differentiating the additives, but the same general trends are present. Our experience with this type of test has indicated that for each range of inhibitor strengths and brine salinity, there is an optimum point in time for the measurement of the kinetics of the precipitation. In the present case, $1 \mathrm{~h}$ appears nearly ideal.

The data of Table 2 reflect several interesting findings. Among the Armak compounds, the data show that increasing the amount of oxyethylene in the molecule decreases, rather than increases, the activity of the compound as a silica precipitation inhibitor. Arquad $18 / 50$, with no oxyethylene, was slightly better than Ethoquad $18 / 25$ (with 15 moles/mole), and significantly better than Ethoquad HT-6OMS ( 50 moles/mole). However, it should be noted that these compounds were tested on a weight, rather than a mole basis, 
Table 1. Characteristics of Effluent Brine during Additive Tests (Magmamax No. 1 we11; flow rate $\sim 100 \mathrm{gpm}$ )

\begin{tabular}{|c|c|c|c|c|c|}
\hline 1979 & $\begin{array}{l}\text { Time } \\
\mathrm{h} \\
\end{array}$ & $\begin{array}{l}\mathrm{SiO}_{2} \\
\mathrm{mg} / \mathrm{kg}\end{array}$ & $\begin{array}{r}\text { Chloride } \\
\text { Mol/1 } \\
\end{array}$ & $\begin{array}{c}\text { Density at } 25^{\circ} \mathrm{C} \\
\mathrm{g} / \mathrm{cm}^{3}\end{array}$ & $\mathrm{pH}$ \\
\hline oct. 24 & 1300 & & 4.04 & 1.163 & \\
\hline 0ct. 30 & 1030 & 474 & 3.95 & 1.159 & $5.90,5.85$ \\
\hline oct. 30 & 1255 & 493 & & 1.158 & 5.89 \\
\hline oct. 30 & 1535 & 495 & 4.08 & 1.166 & 5.93 \\
\hline $0 \mathrm{ct} .31$ & 0800 & 491 & 4.00 & 1.162 & $5.90,5.85$ \\
\hline $0 c t .31$ & 1025 & 501 & & 1.164 & $5.86,5.83$ \\
\hline 0ct. 31 & 1300 & 500 & & 1.164 & $5.85,5.87$ \\
\hline Nov. 1 & 0805 & 502 & 4.06 & 1.163 & 5.88 \\
\hline Nov. 1 & 1035 & 502 & & 1.162 & $5.81,5.85$ \\
\hline Nov. 1 & 1315 & 509 & 4.08 & 1.162 & $5.80,5.74$ \\
\hline Nov. 2 & 0815 & 524 & 4.09 & 1.163 & $6.00,5.94$ \\
\hline Nov. 2 & 0950 & 505 & 4.06 & 1.165 & $6.01,5.98$ \\
\hline Nov. 3 & 0810 & 508 & 4.17 & 1.166 & $5.92,5.94$ \\
\hline Nov. 4 & 0820 & 511 & 4.07 & 1.164 & 5.93 \\
\hline Nov. 5 & 0815 & 506 & 4.16 & 1.167 & $5.96,6.01$ \\
\hline Nov. 6 & 0815 & 509 & 4.08 & 1.164 & 5.96 \\
\hline Nov. 7 & 0830 & 486 & 4.16 & 1.166 & $5.73, a .87$ \\
\hline Nov. 7 & 1310 & 508 & & & \\
\hline Nov. 8 & 1030 & 507 & 4.08 & 1.165 & $5.75,^{\mathrm{a}} 5.98$ \\
\hline Nov. 9 & 0820 & 505 & 4.06 & 1.165 & 5.82 \\
\hline
\end{tabular}

axperiment with Ethoquad plus HCl 
Table 2. Effect of Additives on Rate of Precipitation of Solids and Silica from Effluent Brine at $90^{\circ} \mathrm{C}$. (Magmamax No. 1 Brine, 4.0-4.1 Mol/1 chloride; $20 \mathrm{ppm}$ active compound)

\begin{tabular}{|c|c|c|c|c|c|}
\hline \multirow[b]{2}{*}{ Additive } & \multicolumn{2}{|c|}{ 1-h incubation } & \multirow[b]{2}{*}{$\begin{array}{c}\text { Suspended } \\
\text { solids, } \\
\mathrm{mg} / \mathrm{kg}\end{array}$} & \multicolumn{2}{|c|}{ 2-h incubation } \\
\hline & $\begin{array}{c}\text { Suspended } \\
\text { solids, } \\
\mathrm{mg} / \mathrm{kg} \\
\end{array}$ & $\begin{array}{l}\mathrm{SiO}_{2} \text { in } \\
\text { filtrate, } \\
\mathrm{mg} / \mathrm{kg}\end{array}$ & & $\begin{array}{l}\mathrm{SiO}_{2} \text { in } \\
\text { filtrate, } \\
\mathrm{mg} / \mathrm{kg}\end{array}$ & $\begin{array}{r}\text { Brine } \\
\text { initial } \\
\mathrm{SiO}_{2} \\
\mathrm{mg} / \mathrm{kg}\end{array}$ \\
\hline ntrol & 305 & 240 & 326 & 196 & 493 \\
\hline
\end{tabular}

Armak:

Arquad $18 / 50$

Ethoquad $18 / 25$

Duoquad T-50

Ethoquad HT-60MS

Duomac T
112

126

145

176

266

130

106

228

199

237

294
424

406

378

348

270
257

200

222

275

311
280

303

304

288

251
474

493

474

495

505

Cordova:

Corcat P-18
Corcat P-100
Corcat P-200
P-100, Quaternized
P-100, chloro-
acetic acid deriv.
P-100, glycidol
derivative

Dynapol:

$\mathrm{PAE} \cdot \mathrm{HCl}$,

M. W. $=120,000$

$\mathrm{PAE} \cdot \mathrm{HCl}$,

M.W. $=25,000$

$\mathrm{PAE} \cdot \mathrm{HCl}$,

M.W. $=25,000$,

Hofmann route
423

405

355

340

318

270

\section{0}

285

286

250

286

303
325

267

276

285

270

252
502

502

502

502

509

509
135

207

355
Miscellaneous:
Mirapol $A-15$
RC-413,
M.W. $=30,000$

RC-412,

M.W. $=10,000$

Schercoquat DAB-90
Crotein BTA
151

166

254

320

347
400

344

202

393

304

251

505

258

294

524

524

astandard deviations of determinations: Solids, $13 \mathrm{mg} / \mathrm{kg} ;$ Silica, $6 \mathrm{mg} / \mathrm{kg}$
500

500

501

501

491 
because that parameter is proportional to cost; thus the trends cannot always be discerned on a more scientific basis. It also should be noted that the compounds were tested on the basis of an equal weight of active ingredient, not necessarily the weight of the product as received. The diquat Duoquad T-50 shows good activity, while the Duomac $T$, an amine salt, does not. These results show again that, in general, the stronger the cationic character (as opposed to nonionic or anionic), the stronger the interaction with silica.

The data for the Cordova compounds (see Table 2) indicate a further trend in greater inhibitor potency with decreasing molecular weight, with the Corcat P-18 (M.W. $=1800$ ) being the best compound. None of the modifications of the Corcat $P-100\left(M . W_{0}=10,000\right)$ were better than $P-100$ itself, on a weight basis. However, on a mole basis, the quaternized version probably would have been nearly equal. The chloroacetic acid derivative was of significantly lower activity, while the glycidol derivative had no effect on the silica at a11. Both of these modifications eliminate the primary- and secondary-amine nitrogens, which appear to be necessary for interaction with the silica. The overall cationic character of the polymer is diminished and no other desirable characteristics are substituted.

In the Dynapol group (see Table 2), the high molecular weight PAE $\cdot H C 1$, which was nominally the same as that tested previously, 3 was clearly the best inhibitor. The low molecular weight compound was significantly less active. The low molecular weight compound synthesized by the Hofmann route appeared to have the effect of a silica flocculant, i.e., it produced a higher level of solids and a lower concentration of silica in the brine than would be found normally. Molecular weight thus is a very sensitive parameter in this series of compounds.

A surprising result was that the high molecular weight PAE.HCl examined in this test series was not, as had been found in the June test series, 3 significantly better as an inhibitor than Ethoquad 18/25. This time they were virtually equal in activity. The brine characteristics of the two series were different; nevertheless, the result is still unique because in all of our previous testing, the relative ranking of individual compounds has been 
maintained through several different levels of salinity. Communication with Dynapol indicated that both the old and new lots of the PAE. HCl came from the same lot of polymer, but they were neutralized with different batches of sodium hydroxide. We rechecked the inhibition behavior of samples of both lots of PAE $\cdot \mathrm{HCl}$, at the same time, each in one channel of the brine treatment test system, with identical results. Thus, assuming that chemical aging effects are absent, it must be concluded that the previous higher-salinity brine conditions led to a relative enhancement of the performance of the PAE• HCl compared to Ethoquad 18/25.

Among the miscellaneous compounds (see Table 2), the polymeric diquat Mirapol A-15 was the best inhibitor, nearly as good as the best in the other three categories. That it performs very well is not unexpected in view of its very strong cationic character and its medium molecular weight polymeric structure. The results for the RC- 412 and RC- 413 cationic polymers are interesting because they parallel the behavior of the PAE.HCl compounds. The trend with molecular weight indicates that still higher molecular weight polymers of this type (which are available) would be more effective. The quaternized protein, Crotein BTA, had no activity toward silica, undoubtedly because a relatively small fraction of the molecule is cationic. The Schercoquat DAB-90 was unusual in clearly accelerating the rate of silica precipitation compared to the untreated brine. The rather large hydrophobic portion of this molecule (see Structure 9 on p. 9) may be the reason for this effect. In many respects this compound is unlike any we have ever tested.

An interesting phenomenon that is always observed during the precipitation kinetics studies is probably worthy of note here. When untreated brine is incubated anaerobically at $90^{\circ} \mathrm{C}$, a pure white precipitate forms. This precipitate of course is predominantly silica, but it also contains $1-2 \%$ of an unidentified iron compound. ${ }^{11}$ When brine containing the precipitate is filtered and the collected precipitate is washed with water, the precipitate rapidly turns orange, presumably because of air oxidation of the $\mathrm{Fe}$ (II) in the iron compound to the Fe(III) state. Such a color change is observed for both untreated brine, and brine treated with additives that are not effective precipitation inhibitors. In contrast, if a good silica precipitation 
inhibitor is present, the white precipitate assumes a pale green color that remains until the precipitate is oven dried. It is possible that the green color is due to an Fe(II) species that has been complexed by the additive and stabilized against air oxidation. In the case of the polyamino and polyimine type compounds, strong complexing via chelate ring formation is favored, and the ether oxygens of the polyoxyethylene chains also are capable of coordinating transition metal ions such as iron. Because the precipitation of hydrolyzed iron or iron hydroxide species in the unstable brine may aid in nucleating the precipitation of silica, 8 it is possible that this complexing of the iron species by the additives may contribute to the observed inhibition of silica precipitation.

\section{Comments on the Mechanism of Inhibition of Silica Precipitation and Scaling}

Our search for organic additives for the inhibition of the precipitation of silica and scaling has been strictly empirical in nature; we have acquired no direct evidence of the detailed mechanism of how the inhibitor compounds are able to retard the precipitation reaction. Nevertheless, in the course of our experiments, a number of interesting patterns and correlations have emerged, which, in the light of known silica and colloid chemistry, suggest certain aspects of the mechanism that are worth outlining for possible future studies in this anea. We have speculated on some of the features of the mechanism in previous publications. 1-4 The recently published treatise by Iler ${ }^{12}$ summarizes all of the studies of the interactions of organic compounds with silica, and much of this knowledge ${ }^{13}$ is directly applicable here. The major differences, of course, are that we are dealing with much higher temperatures, flow rates, and solution ionic strengths than are commonly encountered.

First of all, it is reasonably clear that the organic additives retard neither the polymerization of silica nor the formation of nuclei of discrete particles of silica. Rather, they act on the particles, once formed, to decrease their rate of aggregation in homogeneous solution, or, in the case of scale formation, the rate of deposition of silica particles on a substrate 
surface. The probable mechanism is the adsorption of the organic molecules on the surfaces of the particles to provide a barrier to their close approach and subsequent aggregation or flocculation. We have no direct indication of whether this stabilization of the colloidal silica is electrostatic or steric. 14,15 However, it is probable that steric effects are the more important ones, because of the pronounced compression of the electrical double layer on particles in contact with this brine; using the formula of Napper, ${ }^{14}$ the thickness of the double layer in Magmamax No. 1 brine (ionic strength $=5.2$ ) is calculated to be $0.15 \mathrm{~nm}$, which is much less than the dimensions of most adsorbing molecules. The fact that fairly high molecular weight compounds are required for stabilization points to steric effects being dominating.

In ideal steric stabilization, the stabilizing molecules anchor themselves to the particles in such a way that the particles are covered with a diffuse layer that is compatible with, or soluble in, the dispersion medium. Strongly anchoring functional groups, which either adsorb or react, are necessary to withstand the dislodgment forces of Brownian motion and fluid shear. We have attempted, in the course of our studies, to find additives that would form strong chemical bonds with the silica; e.g., a series of silanes was tested, ${ }^{2}$ but no substance has been evaluated that gave evidence of an irreversible reaction. Thus, to the extent the stabilizing molecules that we have found are effective, it appears that physical adsorption is the mechanism of attachment. The nature of the solubilizing moiety is also important. It must be strongly hydrophilic to keep the silica particles dispersed in the high-temperature highly saline brine. Additives that render the particles surfaces hydrophobic probably promote aggregation by "hydrophobic bonding." 16 This may be the reason why certain additives that we have examined (e.g., the Austral-Erwin oil additive ${ }^{5}$ and Schercoquat DAB-90) caused enhanced flocculation or scaling.

A fascinating aspect of our findings is that many of the substances and types of compounds that we have found to be good inhibitors of silica precipitation are used in other applications such as water treatment to flocculate silica. This is not too surprising, however, because strong 
bonding to silica by large organic molecules is well known to lead to either dispersion or flocculation of colloids, depending on the particular conditions, especially the concentration of the organic compound. This sensitivity to concentration is important to note in geothermal applications, where trials of new compounds under new conditions are undertaken.

The questions of how the organic molecules are bonded to the silica surface and how these molecules are oriented in the adsorbed layer are open to further speculation. The answers to these questions could provide the basis for selecting still more potent inhibitors. Important factors that determine the nature of the adsorption of organic molecules on silica surfaces are the ion ic charge on the silica and the neutral salt concentration of the solution. 13 The point of zero charge (isoelectric point) of polymerized silica is at a pH of approximately 2,17 thus in the geothermal brines at $\mathrm{pH}$ 5 to 6 , the colloidal silica surface is composed of neutral - $\mathrm{SiOH}$ and ionized $\mathrm{SiO}^{-}$groups. Organic molecules can adsorb on the surface in three ways ${ }^{18}$ : by London-van der Waals interaction, ionic attraction, and hydrogen bonding. The effect of neutral salt as mentioned above, is to drive the (positive) counterions closer to the charge sites, and make the surface more accessible to adsorption processes. Ionic attraction is undoubtedly the mode by which the quaternary ammonium compounds adsorb and stabilize the colloidal silica, while the nonionic polyoxyethylene polymers and some of the nonionic surfactants act via hydrogen bonding to the ether oxygens. Compounds such as Ethoquad $18 / 25$ that are both positively charged and also contain hydrogenbonding polyoxyethylene chains could have a dual functionality. Both hydrogen bonding and favorable ionic attraction could also be operative in the cases of the nitrogen-containing polymers corcat $\mathrm{P}-18, \mathrm{PAE} \cdot \mathrm{HCl}$, and $\mathrm{RC}-413$, since these substances probably exist as amine salts at the $\mathrm{pH}$ of the brine. These interactions would be very $\mathrm{pH}$ sensitive, e.g., lowering the pH of the brine would reduce the charge density on the silica, but increase the ionic character of the amines. At lower $\mathrm{pH}$, the silica surface would be more favorably disposed to hydrogen bonding, since - SiOH groups predominate; at higher $\mathrm{pH}$, the increasing fraction of $-\mathrm{SiO}^{-}$sites would favor ionic attraction. 
To produce steric stabilization of the colloidal silica, the adsorbed molecule must create sufficient potential energy of repulsion to overcome the London-van der Waals attractive forces between particles that lead to flocculation. The size (or molecular weight) of the adsorbing compound and its conformation on the surface thus are important in determining its effectiveness as an inhibitor of precipitation. 14,15. The presence of these factors are evident in the molecular weight effects that we have observed. Relatively small molecules such as polyoxyethylene of M.W. $\approx 1000$ (Union Carbide Carbowax 1000) $)^{1}$ and small quaternary ammonium salts such as $\mathrm{N}$-(3-chloro-2-hydroxypropyl) trimethylammonium chloride (Dow Chemical Quat $188)^{2}$ were not good inhibitors. Above a molecular weight of 1000 , adsorbed molecules become good inhibitors, and the molecular weight at which there is maximum activity is different for the different classes of compounds.

To a first approximation, it appears that the molecular weight of maximum activity is related to the basic structure type of the molecule and the degree to which it projects into the liquid phase when adsorbed. Thus, in the case of non-polymeric quaternary ammonium compounds (such as Ethoquad 18/25 and Hyamine $1622^{2}$ ) and the polyethylene imines (e.g., Corcat P-18, M.W. $\approx 1800$ ), which are non-linear, branched molecules, relatively low molecular weight molecules are good inhibitors. The polyethylene imines, especially, are highly-branched, three-dimensional networks of approximately spherical shape. 19 The lower molecular weight compounds also have the advantage of higher mobility in solution, so that their rate of adsorption could be higher.

The peak activity of the polyoxyethylenes occurs at a molecular weight of $14,000.1$ This higher value than that of the quaternary ammonium compounds and polyethylene imines may be related to the fact that the polyoxyethylenes are linear chains that can lie relatively flat on the surface of the silica. However, these chains, because of the high ionic strength of the brine, are highly coiled in solution. ${ }^{20}$ Their conformation on the surface is probably really that of loops resulting from random attachment of several segments. This is an intermediate situation between that of completely flat layer adsorption and the maximum extension of a chain attached at one point. The latter is more akin to the situation with the polyethylene imines. 
Chemically somewhat similar to the polyoxyethylenes are the hydroxyethylcellulose polymers. Both substances are nonionic but the cellulose polymers are known to be much more rigid molecules. 21 They were tested at molecular weights of 285,000 and $2,000,000$; the former was the better inhibitor (not quite as good as the Carbowax 14,000), but the opt imum molecular weight has not been determined.

The polymeric nitrogen-containing compounds, PAE. HCl and RC-413, appear to be most effective in the molecular weight range of 1100,000 (an exception was polyethyloxazaline, 2 but insolubility may have contributed to the observations here). Because the highly cationic polymers are easily hydrated and soluble, and are essentially highly-extended chains in solution, they probably adsorb more nearly as very thin monolayers than the other compounds, and this could influence the size of the molecule that is needed for good steric stabilization. Note that in our testing of the compounds on a weight basis, for the same concentration there are approximately the same number of carbon atoms present. Thus for the polyamines, the greater activity at higher molecular weights means that the fewer molecules present are more efficient, perhaps because they probably do not lie as flat on the surface as a greater number of smaller molecules.

A systematic research program to investigate many of these purely speculative aspects of the observed stabilization of colloidal sitica in geothermal brine could prove to be very worthwhile. The effects of the high temperatures and high salinities, in particular, appear to have received little attention in the field of colloid science, because until now there were few applications.

\section{Results of Additional Precipitation Tests during}

\section{Scaling Rate Measurements}

Three of the candidate additives and three combinations of additives were evaluated as antiscalants during the course of this test series. Each was tested in a $40-h$ run to determine its effect on the scaling rates at 220,125 , and $290^{\circ} \mathrm{C}$. During these runs, silica precipitation tests were also carried 
out on the brines, and the corrosion rates of mild steel (AISI 1018) in the additive-treated brines were estimated using the Petrolite Instruments linear polarization resistance (LPR) equipment.

A summary of the additives that were tested, together with the concentrations of active ingredient used, and the results of the silica precipitation tests are given in Table 3. The combination of Mirapol A-15 and Cycloryl NA was tested as an attempt to form a more tenacious adsorbed film on the silica particles. In hair preparations, 10 the cationic polymer Mirapol $A-15$ is first adsorbed on the substrate; then an anionic surfactant such as the Cycloryl NA (sodium lauryl ether sulfonate) reacts with the Mirapol A-15 to form a second film having a hydrophobic exterior. Combinations such as this are also used in other applications to increase film strength. To test the effect of these compounds on geothermal scale, we injected the Mirapol A-15 at the usual point in the system (see Figure 1), and at the same time injected the solution of Cycloryl NA in the second-stage, $125^{\circ} \mathrm{C}$, flash vessel. A disadvantage of this method was that the effect of the combination of compounds on the $220^{\circ} \mathrm{C}$ scale could not be measured. However, this sequential addition of compounds was desirable to test the idea of the bilayer film, and was necessary because these two compounds together formed a precipitate at the stock solution concentrations used.

The results of measurements of the rates of precipitation of solids and silica for the Mirapol A-15/Cycloryl NA combination (Table 3) show only a slight, if any, improvement over the rates found for Mirapol alone (see Table 2). Filtrations during these measurements showed some evidence of additional suspended solids -- possibly a precipitate from the interaction of the two additives. Also, as is summarized below, there was an enhancement of the scaling rate at $125^{\circ} \mathrm{C}$, and the scale seemed to have a hydrophobic character. Thus this brine treatment appears to be another example of a type which must be termed counterproductive, i.e., colloid stabilization in which the solubilizing moiety is hydrophobic. In retrospect, it is obvious that the anionic component of this combination probably should not have been a surfactant. 
Table 3. Effect of Additives on Rate of Precipitation of Solids and Silica from Effluent Brine at $90^{\circ} \mathrm{C}$ (Magmamax No. 1 Brine, 4.0-4.2 Mol/1 chloride)

\begin{tabular}{|c|c|c|c|c|c|}
\hline Additive & $\begin{array}{l}1-h \text { in } \\
\text { Suspended } \\
\text { solids } \\
\mathrm{mg} / \mathrm{kg} \\
\end{array}$ & $\begin{array}{l}\text { Siotion } \\
\mathrm{Silt}_{2} \text { in } \\
\text { filrate } \\
\mathrm{mg} / \mathrm{kg} \\
\end{array}$ & $\begin{array}{l}2-\mathrm{h} \text { in } \\
\text { Suspended } \\
\text { solids } \\
\mathrm{mg} / \mathrm{kg} \\
\end{array}$ & $\begin{array}{l}\text { ation } \\
\text { SiO2 in } \\
\text { filtrate } \\
\mathrm{mg} / \mathrm{kg}\end{array}$ & $\begin{array}{c}\text { Brine } \\
\text { initial } \\
\mathrm{SiO}_{2} \\
\mathrm{mg} / \mathrm{kg} \\
\end{array}$ \\
\hline $\begin{array}{c}\text { Mirapol A-15 } \\
(20 \mathrm{ppm}) \\
+ \\
\text { Cyclor ol NA } \\
(20 \mathrm{ppm})\end{array}$ & 112 & 404 & 196 & 321 & 508 \\
\hline $\begin{array}{l}\text { Ethoquad 18/25 } \\
\quad(25 \mathrm{ppm}) \\
+ \\
\text { Duomac T } \\
(7 \mathrm{ppm})\end{array}$ & 87 & 425 & 160 & 357 & 506 \\
\hline $\begin{array}{c}\text { Corcat P-18 } \\
(35 \mathrm{ppm})\end{array}$ & 128,146 & 416,412 & 223 & 339 & 506 \\
\hline $\begin{array}{l}\text { Ethoquad 18/25 } \\
\qquad(27 \mathrm{ppm})\end{array}$ & & & & & \\
\hline $\mathrm{HCl}(100 \mathrm{ppm})$ & 34 & 462 & 53 & 458 & 486 \\
\hline $\begin{array}{l}\text { Ethoquad } 18 / 25 \\
\text { (35 ppm) }\end{array}$ & 90 & 436 & 235 & 321. & 486 \\
\hline $\begin{array}{l}\mathrm{PAE} \cdot \mathrm{HCl} \\
(35 \mathrm{ppm})\end{array}$ & 115 & 431 & 235 & 327 & 505 \\
\hline
\end{tabular}


The second combination tested, Ethoquad 18/25 and Duomac $T$, which were mixed together and added as a single solution, comprised a silica precipitation inhibitor and a corrosion inhibitor used in other applications. The latter has virtually no activity as a silica precipitation inhibitor (see Table 2), thus the effect of the combination in this test (see Table 3 ) is about the same as that of the Ethoquad $18 / 25$ alone. There was no indication of undesirable behavior in the precipitation tests, but there was an enhancement of the scaling rate at $125^{\circ} \mathrm{C}$ compared to the untreated brine, and compared to the effect of Ethoquad alone. In this case, the failure is possibly due to limitations in the solubility of the Duomac $T$ in the brine, a characteristic that we previously attributed to other long chain amines. ${ }^{1}$

The combination of Ethoquad $18 / 25$ and hydrochloric acid was designed to test the effect of a combination of a silica precipitation inhibitor with a "small" amount of acid. Many previous investigations $3,8,22$ have shown that lowering the $\mathrm{pH}$ of the brine effectively decreases the rates of silica precipitation and scaling; however, for this brine, a concentration of at least $300 \mathrm{ppm} \mathrm{HCl}$ is required to lower the $\mathrm{pH}$ of the effluent brine from $\sim 5.9$ to 25.0 where antiscalant activity becomes measurable. This corresponds to a concentration of $\sim 800 \mathrm{ppm}$ of the $37 \%$ concentrated acid, and it represents a rather high chemical cost; thus it is of interest to know whether a combination of acid and organic inhibitor could be rendered cost effective. For the one experimental trial in the time available, we selected an amount of Ethoquad $18 / 25$ in the range usually used and a relatively small amount of hydrochloric acid (100 ppm HCl) that was not expected to change the $\mathrm{pH}$ of the brine to a great extent. The resulting $\mathrm{pH}$ change was indeed not large, from 5.9 to $\sim 5.7$, but as shown in the data of Table 3 , this quantity of acid significantly enhances the retardation of the precipitation of silica compared to Ethoquad $18 / 25$ alone. As will be discussed below, the acid also is very beneficial as an antiscalant, but its effect in this measurement was somewhat obscured by the behavior of the Ethoquad. For these experiments, the Ethoquad and hydrochloric acid were mixed together and injected at the usual high temperature point. 
The three compounds that were tested alone, Corcat P-18, Ethoquad 18/25, and $\mathrm{PAE} \cdot \mathrm{HCl}$, were evaluated at a concentration of $35 \mathrm{ppm}$, which is higher than the $20 \mathrm{ppm}$ concentration of the precipitation screening tests, and higher than the $20-25 \mathrm{ppm}$ tested in previous scale abatement measurements. ${ }^{3}$. This higher concentration was selected because time was not available for a study of the effect of concentration, and we wanted to increase the probability that a measurable effect of the additives would be observed. On the other hand, it is quite desirable to use as low a concentration of additive as possible because of ultimate chemical costs and because overfeeding of ten results in the enhancement of scale deposit formation (sometimes termed "pseudoscale" ${ }^{\prime 23}$ ). In any event, optimization of the effect of the additive vs. concentration should always be done.

The results of the silica precipitation rate measurements, as given in Tables 2 and 3, show that increasing the concentrations of additives from 20 to $35 \mathrm{ppm}$ slightly enhanced the inhibition effect for the Ethoquad $18 / 25$ and PAE.HCI but not for the Corcat P-18. It has been noted previously ${ }^{3}$ that the concentration dependence is quite pronounced in certain ranges and that in general, for all of the organic additives we have examined, ${ }^{1-3}$ a concentration of $\sim 40 \mathrm{ppm}$ is the point at which further improvement is marginal. The reason for this interesting finding is unknown, but this limit may be related to the concentraton at which silica particle coverage is complete under our particular kinetic and hydrodynamic conditions. Another possibility in the case of some of the surfactants like Ethoquad $18 / 25$ is that the concentration limit is related to the critical micelle concentration ${ }^{24}$ of the additive in this brine.

\section{Electrochemical Corrosion-Rate Measurements}

Table 4 summarizes the results of the measurements of corrosion rates obtained with the Petrolite Instruments equipment. The values of corrosion rates listed are those indicated after $40 \mathrm{~h}$ exposures -- near the terminations of the scaling rate experiments - when the corrosion rates had reached nearly steady values. Figure 2 illustrates how the indicated 
Table 4. Steady State Corrosion Rates of Mild Steel (AISI 1018) in Additive-Treated Brine as Estimated by the Linear Polarization Resistance Technique.

\section{Corrosion rate, mpy}

Additive $^{\mathrm{a}}$

None, Control

Mirapol A-15 + Cycloryl NA

Ethoquad 18/25 + Duomac T

Corcat P-18

Ethoquad $18 / 25+\mathrm{HCl}$

Ethoquad 18/25

PAE $\cdot \mathrm{HCl}$ $220^{\circ}$

15

6

8

8

17

8

15 $125^{\circ}$

5

2.4

2.0

1.0

20

1.2

2.0

See Table 3 for concentrations of additives. 
CORROSION RATES OF MILD STEEL AT $125^{\circ} \mathrm{C}$ ESTIMATED BY LPR TECHNIOUE

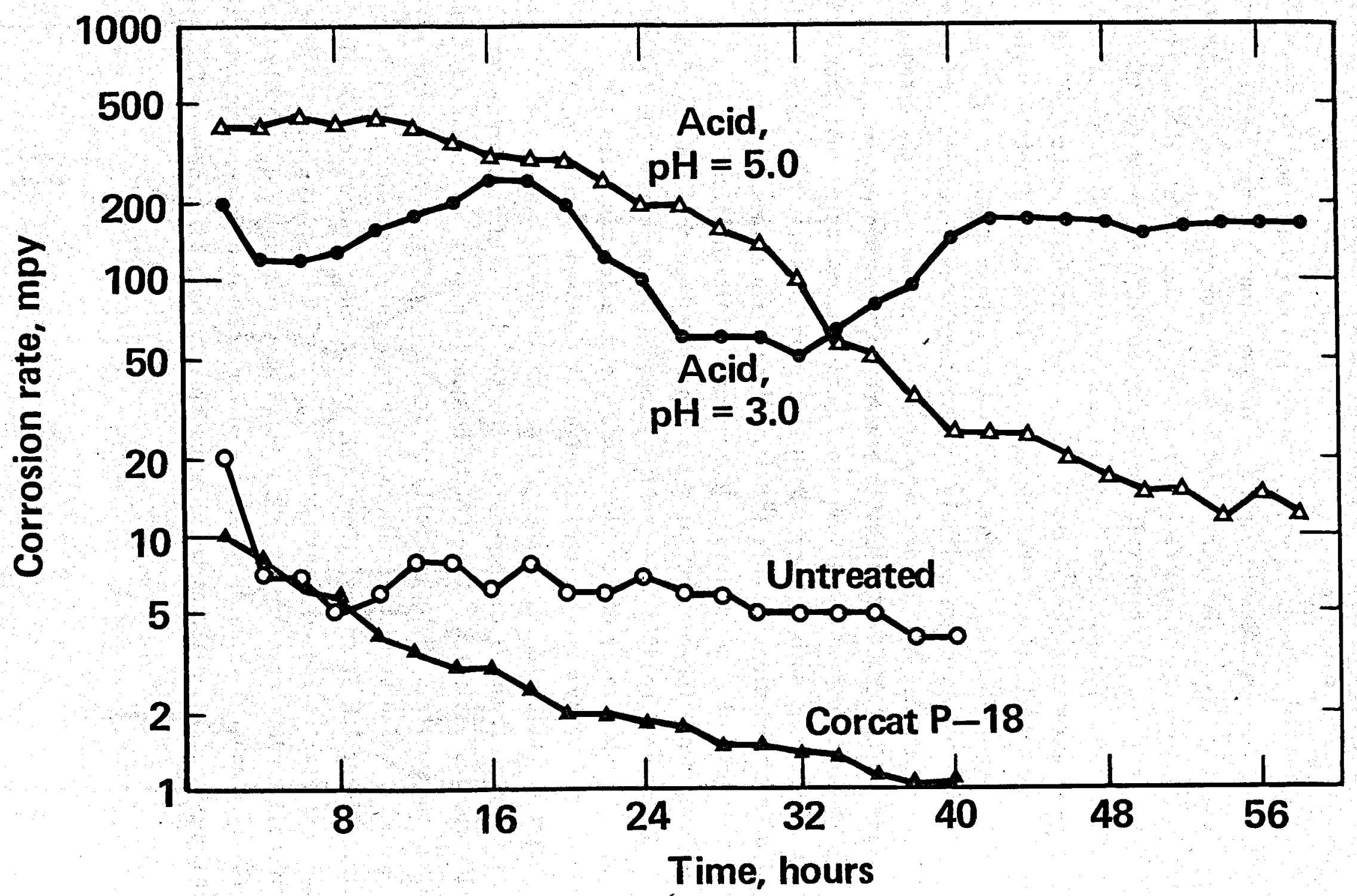


corrosion rates vary for several types of brine treatment using this technique. The measurements of acidified brine were obtained in a previous study. 3

Most of the differences in values listed in Table 4 may not be very significant since considerable variation in corrosion rate has been observed for untreated brines in the course of the year's experiments. At $200-220^{\circ} \mathrm{C}$, previous corrosion rates have ranged from 4 to $11 \mathrm{mpy}$, and at $125^{\circ} \mathrm{C}$ from 7 to $22 \mathrm{mpy}$. However, the high value of $17 \mathrm{mpy}$ at $220^{\circ} \mathrm{C}$ observed for the brine treated with Ethoquad and acid has been verified. The corresponding scaling-rate specimen at $220^{\circ} \mathrm{C}$ was the only one that lost weight (see Table 5 below), and calculation of the corrosion rate from this weight loss yields a value of $20 \mathrm{mpy}$. The very low values of 1 to 2 mpy observed for the other additives at $125^{\circ} \mathrm{C}$ also are probably realistic and represent some corrosion inhibition behavior. A value of $2 \mathrm{mpy}$ at $125^{\circ} \mathrm{C}$ was found for the Ethoquad 18/25-Dequest 2060 combination tested previously, 3 and Dequest phosphonate-type compounds are known to function as corrosion inhibitors. 25 Polyethylene imines such as Corcat $P-18$ have been used as corrosion inhibitors for mild steel in chloride media, 26,27 and long chain amines such as PAE HCl should also exhibit such activity. Corrosion inhibition is certainly a desirable property for a potential scale inhibitor because (a) the siliceous scale adheres more readily to a surface roughened by corrosion, and (b) suppression of the entry of $\mathrm{Fe}^{2+}$ ions into the solution minimizes the formation of $\mathrm{Fe}^{2+}$ hydrolysis species which, it has been speculated, 8,28 are important nuclei for the deposition of the siliceous scale.

As shown in Figure 2 the corrosion rate for $\mathrm{pH} 3$ acidified brine remains at $\sim 100 \mathrm{mpy}$, as estimated by the LPR technique. This is consistent with the

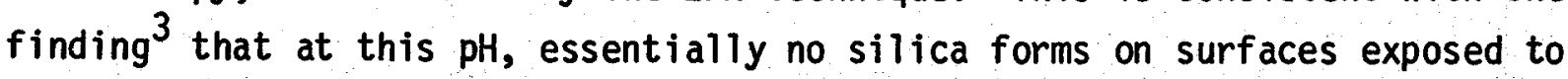
the brine, and mild steel is found to accumulate only corrosion product. Acidification to $\mathrm{pH} 5$, on the other hand, is not sufficient to completely suppress silica scaling from this brine. ${ }^{3}$ The apparent corrosion rate thus continuously drifts downward for the first 3 days exposure and probably would eventually reach the value of 25 mpy found for untreated brine. The inhibitor action of the Corcat P-18 can be inferred clearly from the curves of Figure 2 . 
Results of Scaling Rate Measurements

Tables 5 and 6 sumarize the results of measurements of the effects of the various additives on the scaling tendency of Magmamax No. 1 brine. At $220^{\circ} \mathrm{C}$, the rate of scaling of untreated brine has always been so low that exposure times of the order of $100 \mathrm{~h}$ are too short for very accurate comparisons by the technique of scale thickness measurement. Thus we include also in Table 5 the data for the measurements of the weight changes of the coupons exposed to the brines. This is a more sensitive indicator of the effects of the additives. As usual, the three different materials -- AISI 1009 mild steel, TFE Tefion, and Hastelloy C-276 -- were exposed to differentiate the effects of corrosion from those of scale deposition.

At $220^{\circ} \mathrm{C}$, there appeared to be an increased rate of scaling as a result of the addition of the Mirapol A-15 to the high temperature brine. We estimate that the reproducibility of these measurements is approximately $\pm 40 \%$. On this basis, it is also clear that the Ethoquad/Duomac combination and Corcat P-18 had no effect. There appeared to be a slight reduction in scaling rate for the Ethoquad $18 / 25$ alone, although the weight gain data for Teflon and Hastelloy do not bear this out. The combination of $100 \mathrm{ppm} \mathrm{HCl}$ with $27 \mathrm{ppm}$ Ethoquad 18/25, and the PAE $\cdot H C 1$ at $35 \mathrm{ppm}$, both clearly reduced the scaling rate at $220^{\circ} \mathrm{C}$. As noted above, the mild steel coupon in the presence of the Ethoquad/HC] lost weight because of general corrosion. Even though there is only a small change in brine $\mathrm{pH}$ as a result of the HCl addition (at least as measured at the effluent point), the effect on scaling rate is significant.

It is also interesting to note that some, if not all of the measured effect of the PAE.HCl at $220^{\circ} \mathrm{C}$ may be due to the concomitant addition of free $\mathrm{HCl}$. Because this additive is a weak hydrochloric acid solution of the polymeric amine, the injection of $35 \mathrm{ppm}$ PAE. HCl is equivalent to the addition of $\sim 30 \mathrm{ppm}$ of $\mathrm{HCl}$. It is possible that this characteristic of the PAE.HCl enhances its activity compared to the other additives that we have tested, and may be reason why the PAE.HCl was superior to the Ethoquad $18 / 25$ in the previous precipitation tests in stronger brine. ${ }^{3}$ All of the other 
Table 5. Effect of Additives on Scaling Rates of Geothermal Brine at $220^{\circ} \mathrm{C}$ (Magmamax No. 1 brine; 4.0-4.2 Mol/1 chloride; $40 \mathrm{~h}$ exposures)

\begin{tabular}{|c|c|c|c|c|c|c|}
\hline \multirow[b]{2}{*}{ Additive } & \multicolumn{3}{|c|}{$\begin{array}{l}\text { Coupon } \\
\text { Scaling rate, mil/h }\end{array}$} & \multicolumn{3}{|c|}{ Weight gain, $\mathrm{mg}$} \\
\hline & $\begin{array}{l}\text { Steel } \\
\text { Sten }\end{array}$ & Teflon & Hastelloy & $\begin{array}{l}M+1 d \\
\text { Steel } \\
\end{array}$ & Tefion & Hastelloy \\
\hline None, Control & 0.03 & 0.03 & 0.02 & 15.7 & 19.4 & 12.4 \\
\hline $\begin{array}{c}\text { Mirapol A-15 } \\
(20 \mathrm{ppm})\end{array}$ & 0.05 & 0.06 & 0.14 & 28.6 & 27.0 & 21.5 \\
\hline $\begin{array}{c}\text { Ethoquad + } \\
\text { Duomac T }\end{array}$ & 0.03 & 0.03 & 0.03 & 18.8 & 8.6 & 14.6 \\
\hline $\begin{array}{l}\text { Corcat P-18 } \\
\qquad(35 \mathrm{ppm})\end{array}$ & 0.03 & 0.03 & 0.02 & 15.5 & 20.6 & 16.5 \\
\hline $\begin{array}{l}\text { Ethoquad + } \\
\text { HCl }\end{array}$ & 0 & $<0.01$ & $<0.01$ & -15.0 & 5.5 & 7.4 \\
\hline $\begin{array}{l}\text { Ethoquad 18/25 } \\
\text { (35 ppm) }\end{array}$ & 0.01 & 0.02 & $<0.01$ & 6.2 & 14.9 & 11.8 \\
\hline $\begin{array}{l}\mathrm{PAE} \cdot \mathrm{HCl} \\
\quad(35 \mathrm{ppm})\end{array}$ & 0.01 & $<0.01$ & $<0.01$ & 4.9 & 9.6 & 1.4 \\
\hline
\end{tabular}

a See Table 3 for concentrations of additive combinations. 
Table 6. Effect of Additives on Scaling Rates of Geothermal Brine at 125 and $90^{\circ} \mathrm{C}$ (Magmamax No. 1 brine; 4.0-4.2 Mol/1 chloride)

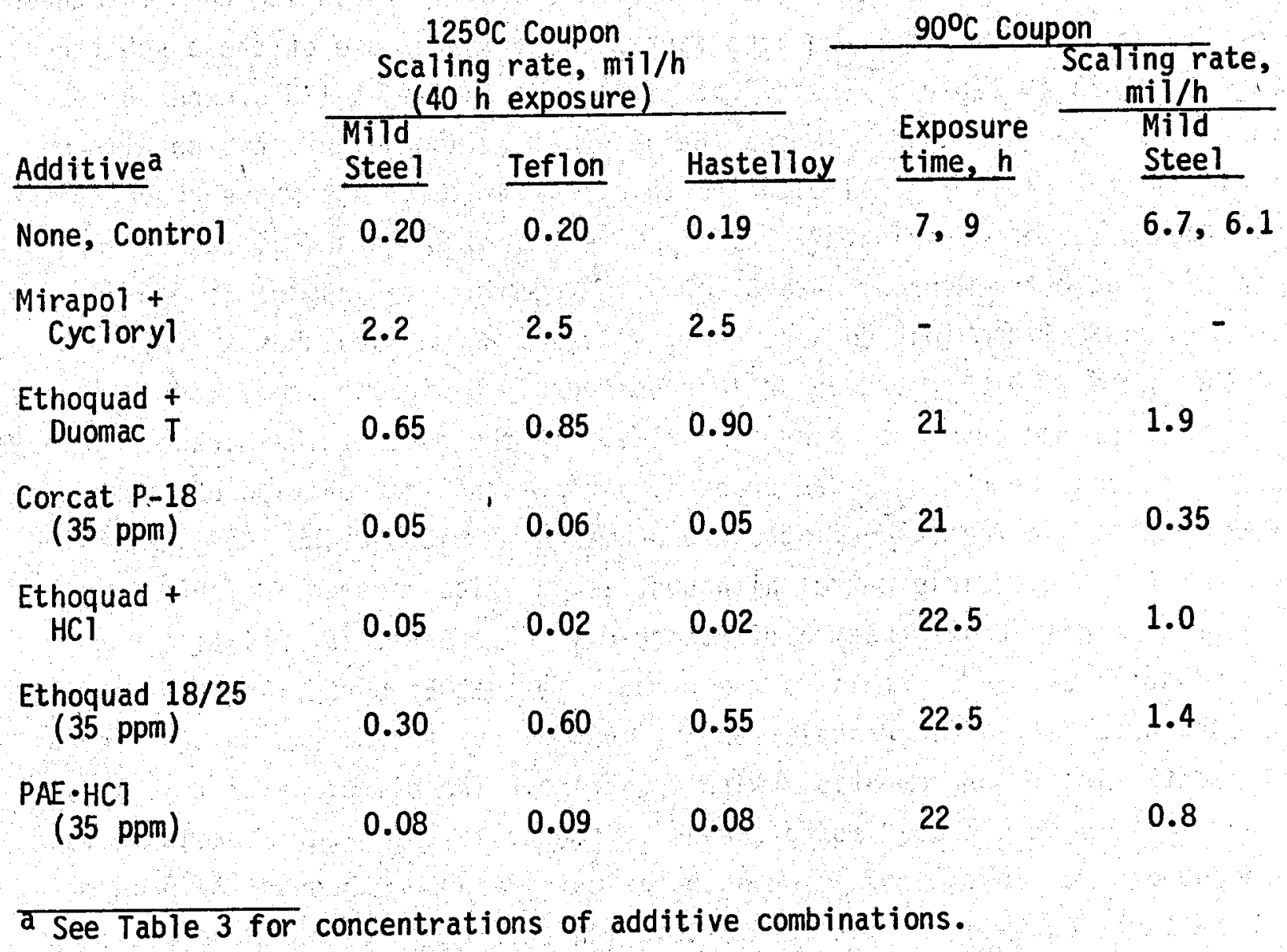


additives that we have tested are weakly acidic, neutral, or in many cases slightly alkaline in reaction. Because of the sensitivity of the silica polymerization reaction to $\mathrm{pH}$, the $\mathrm{pH}$ of the additive solution and its manner of mixing with the brine are important factors in the use of these substances. As shown in Table 6 , the effects of the additives at $125^{\circ} \mathrm{C}$ were quite diverse. Here the coupon weight changes (all gained weight) are not listed, because they closely paralleled the thickness measurements whose accuracy is estimated to be approximately $\pm 25 \%$. As mentioned above and as can be seen in Table 6, both the Mirapol A-25/Cycloryl NA combination and the Ethoquad $18 / 25$-Duomac $T$ combination were unsatisfactory as antiscalants at $125^{\circ} \mathrm{C}$. Both formed a thick, powdery scale considerably different from, and in excess of, that formed from the untreated brine. In the case of the Mirapol/Cycloryl mixture, this pseudoscale was probably a result of the reaction of these two components. In the case of Ethoquad/Duomac combination, insolubility of the Duomac $T$ is a possible cause, although, as can also be seen in Table $6, a$ slightly higher concentration of Ethoquad 18/25 (35 vs. $25 \mathrm{ppm}$ ) also caused a pseudoscale as $125^{\circ} \mathrm{C}$. This is the first time that Ethoquad $18 / 25$ has been observed to form a pseudoscale, and it must be due to the use of too high a concentration to be compatible with the brine. The discovery of this limit for overfeeding Ethoquad 18/25 serves to emphasize the need to evaluate each compound as a function of its concentration. Because Ethoquad 18/25 is a surfactant, capable of micellar association and formation of hydrophobic entities, and contains fairly long chains of polyoxyethylenes, it may have a greater propensity than the strongly cationic polymers toward insolubility.

At $125^{\circ} \mathrm{C}$, both Corcat $\mathrm{P}-18$ and $\mathrm{PAE} \cdot \mathrm{HCl}$ significantly reduced the scaling rate, and the combination of Ethoquad and $\mathrm{HCl}$ was best of all, especially for the surfaces that did not corrode (see Table 6, Teflon and Hastelloy). Unlike the harder scale formed from untreated brine, the scale formed in the presence of these three additives was soft, powdery, and easily removed from the coupons, especially from the noncorroding specimens. It is noteworthy that, to the extent that the Ethoquad 18/25 alone may cause a pseudoscale, the presence of the acid more than compensates for it. The higher corrosion rate of $20 \mathrm{mpy}$ at $125^{\circ} \mathrm{C}$ for this mixture (see Table 4) also is consistent with 
the apparent reduction in scaling rate. Additional experiments with combinations of acid and the other silica precipitation inhibitors Corcat P-18 and PAE.HCl obviously should have been performed, but this was precluded by our sequence of experimentation and limitations on the field testing time. At $90^{\circ} \mathrm{C}$, the $\frac{1}{4}$-inch tubing specimens showed a dramatic reduction in the scaling rate as a result of the presence of Corcat P-18 in the brine (see Table 6), and the pure white appearance of the scale that was formed further indicated that Corcat P-18 acted as a corrosion inhibitor as well. The reduction in scaling rate and corrosion was less pronounced, but still very good, for PAE.HC1. Ethoquad $18 / 25$ was more effective in this experiment, at $35 \mathrm{ppm}$, than previously at $25 \mathrm{ppm}, 3$ and the combination with $\mathrm{HCl}$ was even better. These scales showed no substantial morphological differences from the scale formed from untreated brine - all are soft, easily removed, and snow-flake-like in appearance. When dried and exposed to air, their whiteness changes to the yellow of $\mathrm{Fe}^{3+}$ species if significant substrate corrosion has occurred. In spite of the unsatisfactory performance of the Ethoquad/Duomac combination at $125^{\circ} \mathrm{C}$, it did afford a significant degree of scale abatement at $90^{\circ} \mathrm{C}$. Our tests have always shown a good general correlation between the precipitation inhibitor tests at $90^{\circ} \mathrm{C}$ and the scaling rate measurements at the same temperature.

\section{Summary, Recommendations, and Conclusions}

The experiments described here constitute the final series in our field testing to find a cost-effective organic compound for the retardation of the siliceous scales of the Salton Sea Geothermal Field. Although terminated (because of a lack of funding), the study cannot be considered completed, for there are additional logical avenues and extensions of this work that should be pursued. As it stands now, we can, however, summarize this investigation, present some recommendations on the best antiscalants we have found thus far, and offer some suggestions for their further evaluation. In addition, some general coments on testing techniques for antiscalants in geothermal applications will be advanced, and some compounds that should be examined in further scale control tests will be mentioned. 
Table 7 summarizes several of the salient characteristics of the four compounds that we now regard as the leading candidates for the abatement of the siliceous scales. These single compounds are regarded as the best silica scale inhibitors; however, as will be discussed below, the best antiscalant additives ultimately will probably be mixtures incorporating such compounds. Although Mirapol A-15 was not tested alone as an antiscalant, it performed very well in the precipitation test and it appears to have many of the other chemical and physical features of a good silica scale inhibitor.

All of the products listed in Table 7 are available as liquids, and, except for the PAE.HCl, at high strength, which facilitates their injection in large scale facilities. However, in such applications, an adequate degree and time of mixing in the brine must be allowed to insure dispersal and solution of the active compound. The active compound, in the diluted form in the brine, should also be allowed to react with the particles of silica as early in the geothermal system as possible. Resistance of the compounds to the high temperatures of the brines is generally not of concern for the short residence times involved. But it has been demonstrated ${ }^{2}$ that additive injection as far upstream in the system as possible, where the particles of silica are the smallest size, yields the greatest activity in inhibition of silica precipitation.

Another property that may be significant in the use of an organic additive as a geothermal antiscalant, depending on the system design, is surface activity and tendency to form a foam. Foaming in steam/brine separators would be detrimental to their operation. Among the four compounds, only Ethoquad 18/25 and Mirapol A-15 impart some foaming tendency to pure water; this is suppressed by the high salt content of the brine at ambient temperatures. The behavior of these compounds at both high-salt and high-temperature conditions with respect to foaming is unknown, but if undesirable, it could be neutralized by means of an antifoam agent.

Future utilization of the brines of the Salton Sea Geothermal Field will probably involve processing of the effluent brine for solids removal prior to injection. 29,30 This involves the use of a reactor/clarifier in which the brine contacts a silica sludge to reduce the concentration of silica in the 
Table 7. Characteristics of leading candidate compounds for the retardation of scale at the Salton Sea Geothermal Field

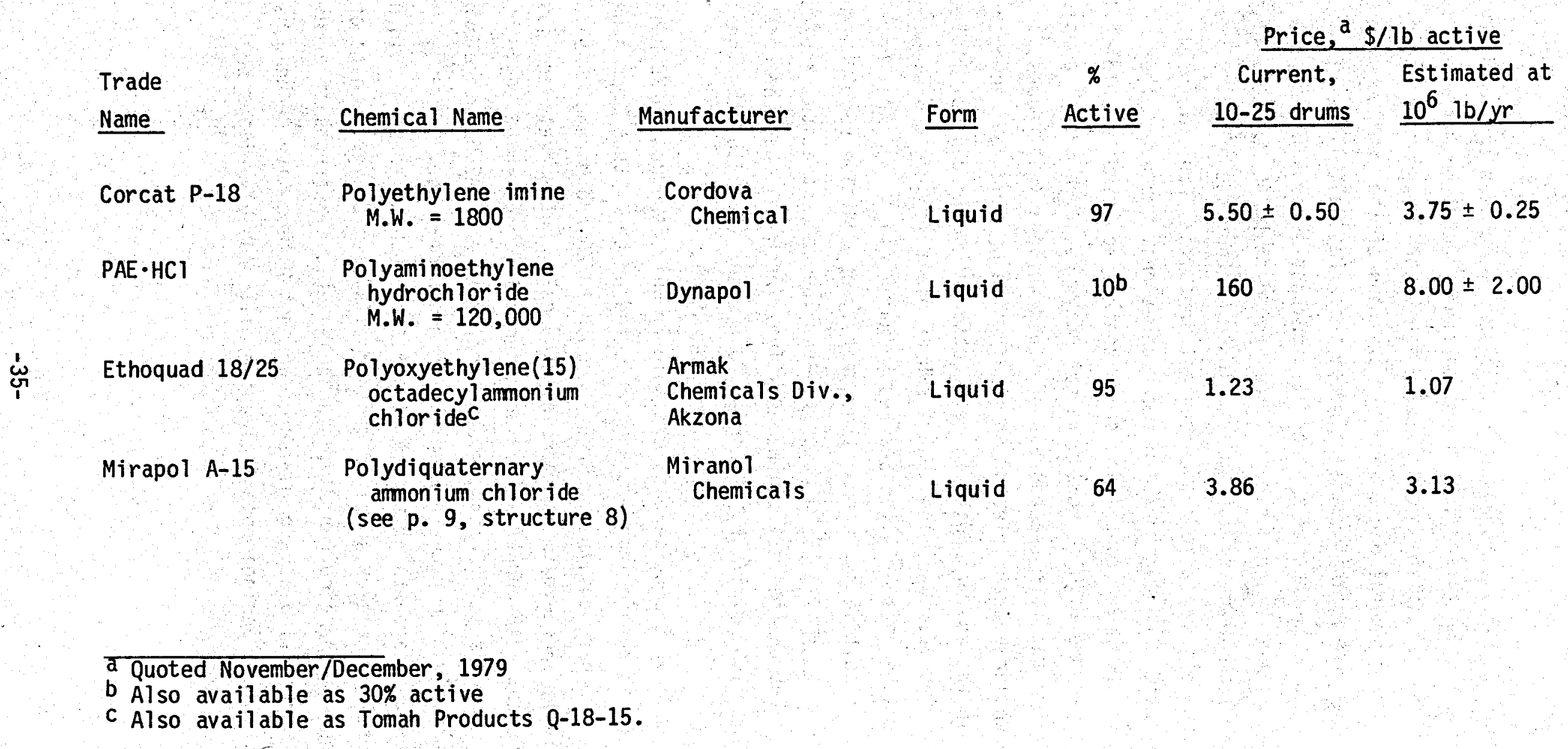


effluent to equilibrium levels at $\sim 90^{\circ} \mathrm{C}$. If such processes are used, the impact of silica precipitation inhibitors on their operation must be assessed. The perfect silica precipitation inhibitor, of course, would obviate such solids removal equipment. In the case of the compounds that we have found to be good inhibitors, it appears that they have little influence on the powerful driving force for precipitation that is provided by the sludge contact. In some recent $\mathrm{jar}$ tests, 31 it was found that PAE. $\mathrm{HCl}$ actually accelerated the removal of silica by the sludge contact technique. Thus it can be concluded that these less-than-perfect inhibitors probably would have no detrimental effect on reactor/clarifier operations. However, the injectability of the brine containing scale control additives should still be examined, because some high molecular weight polymers, even though completely soluble, are known to limit the passage of fluid through small pores. ${ }^{32}$

Because such large quantities of chemical would be required, an overriding consideration in the use of additives for geothermal scale control is the cost of the additive itself. Assuming that $1 \mathrm{kWh}$ of electricity could be generated from $100 \mathrm{lb}$ of brine at the Salton Sea Geothermal Field, ${ }^{33}$ and the concentration of additive is $20 \mathrm{ppm}$, the quantity of additive required would be 1 ton/day for a typical $50 \mathrm{MW}$ power plant. The concentration required places a constraint on the cost of the additive. Assuming that the cost of power generation is $33 \mathrm{mill} / \mathrm{kWh}, 33$ then at $20 \mathrm{ppm}$ and $\$ 2.00 / 1 \mathrm{~b}$, the additive would represent $\sim 12 \%$ of the cost of power generation.

As can be seen in the price data of Table 7, only Ethoquad 18/25 has a current price -- or even a large-volume projected price -- that approaches the cost constraint we have outlined. Both Ethoquad 18/25 and Mirapol A-15 are already relatively large-volume commercial chemicals, but markets are just emerging for Corcat P-18 and PAE:HCl. Unfortunately, because of their complexity of manufacture, the prices of Corcat P-18 and PAE-HCl, are expected to remain relatively high even if adopted for geothermal use.

Nevertheless, it appears that cost comparisons such as these should be done very carefully for each specific geothermal system design. Costs of various options are changing rapidly, and the beneficial effects of a chemical additive treatment will always be measured against alternative techniques of scale control. Since periodic plant cleaning will probably always be 
required, the frequency of cleaning will serve as the basis of comparison of the various alternative techniques. Moreover, the ease of removal of the scale as a result of brine treatment, as well as the degree of scale abatement, should be a consideration in evaluating a candidate additive. All of these additives appear to render the scale easier to remove at the lower temperatures.

Based on the various criteria of merit that we have discussed and the performance of these compounds as an antiscalants, we believe that Corcat P-18 is the most promising single compound. It has good physical properties, is a low molecular weight polymer, and there is good evidence that it also functions as a corrosion inhibitor. An ideal additive mixture might be composed of the following:

\section{Corcat P-18}

Hydrochloric acid

Dequest 2060

As has been demonstrated, hydrochloric acid confers antiscalant activity in the $200^{\circ} \mathrm{C}$ regime, and it enhances the effect of the silica precipitation inhibitor at lower temperatures. A total cost advantage could be gained by trading off a quantity of the Corcat $\mathrm{P}-18$ for the much less expensive $\mathrm{HCl}$ $(\sim \$ 0.10 / 7 \mathrm{~b})$. As has been shown, concentrations of $\mathrm{HCl}$ of at least $100 \mathrm{ppm}$ do not greatly increase the corrosivity of the Niland brine. Also, brief tests of the effect of acidification on the operation of our centrifugal separator have shown very little carryover of HCl in the steam. Dequest 2060 (Monsanto diethylenetriamine pentamethylene phosphonic acid) is suggested as a component because it is effective as an inhibitor of crystalline (e.g., $\mathrm{CaCO}_{3}$ and $\mathrm{CaSO}_{4}$ ) scales and has been shown to be synergistic in combination with Ethoquad $18 / 25$. $^{3}$

PAE.HCI could be substituted for Corcat $P-18$ in this formulation - - it has the advantage that the $\mathrm{HCl}$ is already present, and it could be supplied in the highly acidic, rather than partially neutralized form. At that stage in the

Note that scale abatement alone tends to increase corrosion rates; this quantity of HCl does not greatly lower the $\mathrm{pH}$ and further increase corrosion. 
manufacture of the compound, 9 the praduct contains 3 equivalents of $\mathrm{HCl}$ per amine group; thus in this form, the addition of $35 \mathrm{ppm}$ of PAE.HCl would entail the concomitant addition of $\sim 100 \mathrm{ppm}$ of $\mathrm{HCl}$, with the resulting beneficial effect. However, according to Dynapol spokesmen, supplying the PAE. HCl without neutralization would not substantially reduce its price.

Our recomendation of these compounds for silica scale control must be regarded at this time as being specific to the brines of the Salton Sea Geothermal field. Nevertheless, they also appear worthy of trials at other resources (e.g., Cerro Prieto, New Zealand, and Raft River, Idaho) where silica precipitation and scaling are also encountered. All other conditions being equal, they may be more effective in the lower salinity brines. If they are evaluated at other resources, investigators should be aware of the many variables that will affect their performance. Indeed, a relative ranking of potency of various compounds may be different in different silica-bearing brines. Factors and variables to be considered in an antiscalant evaluation are the following:

Brine $\mathrm{pH}$. This factor is complex because it determines both the ionic form of the additive compound and the state of the surface of the silica particles. For example, compared to the Niland brine $\mathrm{pH}$ of 5-6, more alkaline brines (such as Cerro Prieto) should cause the silanol groups on the silica to be more highly ionized, imparting a higher density of negative charges, and making cationic additives more strongly adsorbed.

Concentration of Additive. This factor is extremely important because the action of a particular compound as an antiscalant may be confined to a fairly narrow concentration range. Compounds that strongly adsorb onto colloidal particles (such as the silica in the geothermal brine) may, at low concentrations, promote scale deposition by acting as bridging flocculants. 16,34 At higher concentrations, where the particles are completely covered by the adsorbed compound, precipitation and scale deposition will be inhibited. At still higher concentrations, the danger of overfeeding and pseudoscale ${ }^{23}$ formation exists. For these 
reasons, new applications of the recommended antiscalants should, if possible, be evaluated first in precipitation tests of the type we have used to determine the effective ranges of concentration. Also, additive feed systems should be designed to be non-pulsating to minimize transient concentration excursions. Brine Salinity. In the case of the Niland brines, it has been found ${ }^{3}$ that the total inert salt concentration profouondly influences the rates of silica precipitation and scale deposition. The higher the salt concentration (or salinity), the more rapidly silica precipitates, and the less effective a given additive becomes in reducing scale deposition. Because of this effect, our comparisons of additives had to be done carefully on an "equal salinity" basis.

Point of Addition of Antiscalant. Several aspects of the manner and location at which the antiscalant is introduced in the geothermal system are worthy of note. Our work has been directed toward the abatement of siliceous scales. Thus we have not been concerned with the sulfide-rich, low silica scales that are formed from the Niland fluid prior to steam separation. After the initial steam separation (at $200-220^{\circ} \mathrm{C}$; see figure 1), silica deposition begins along with additional sulfide formation, and the scales contain $40-50 \%$ silica. 5 We had hoped to discover an organic compound that would control this scale as well as those at lower temperatures, but it appears that on $1 y$ acid, or acidic additives such as PAE $\cdot \mathrm{HCl}$, are effective above $\sim 180^{\circ} \mathrm{C}$.

Nevertheless, as mentioned above, we believe it is very important to inject the organic additive as early in the system as possible so that the adsorbing compound can react with the silica particles in their incipient growth stage. (Insufficient residence times at temperatures $180^{\circ} \mathrm{C}$ in our system may be one reason for the lack of antiscalant activity.) We have found a considerable decline in activity of silica scale inhibitor 
activity as the point of addition of inhibitor approaches the effluent stage. Thus wellhead or pre-first-stage injection is recommended, if possible, even though antiscalant activity might not be realized at that point.

The types of compounds that have emerged from our testing as effective silica scale inhibitors quite naturally suggest other related compounds that should also be examined in further tests at the Salton Sea Geothermal Field, or with brines at other geothermal sites. Among compounds we have already tested, but only as precipitation inhibitors, two compounds appear to merit further evaluation: Armak's Arquad 18/50, which is structurally similar to Ethoquad $18 / 25$ (see p. 5 of this report, and is almost as potent; and Rohm and Haas' Hyamine 1622 , which was tested earlier. ${ }^{2}$ Both products are quaternary ammonium compounds without polyoxyethylene. (It is ironic that we now believe that the polyoxyethylene moiety is not a prerequisite for effectiveness in scale control.) As noted above, higher molecular weight versions of the American Cyanamid RC-series cationic polymeric tertiary amines should also be tested.

Another compound of interest, which is recommended for use in silicosis therapy but is only available in research quantities, is poly-(2-vinylpyridine $\mathrm{N}$-oxide). 35 Other $\mathrm{N}$-oxides are also known to form strong hydrogen bonds with silica. 36 However, these substances are anionic and they are said to bond to non-ionized silanol groups, thus they may not be as effective toward the negatively charged silica particles in the geothermal brines. Finally, there are a number of other cationic polymers of various types, 37,38 which are used principally as flocculants in water treatment and in mineral flotation, which should be evaluated as silica antiscalants; they may offer cost advantages.

Since the field test series discussed herein was the final one of this investigation, it may be of interest to enumerate briefly a few of the facts about the overall scale control investigation that began in late 1977. We initially tested 49 organic compounds off-line to obtain a first indication of the functional groups that interacted with silica in the hypersaline brine. 39 A total of 16 proprietary and 59 generic (chemically identified) compounds were then evaluated by means of either precipitation or 
scaling tests using the pilot-scale brine treatment test system (Figure 1). In addition, the effects of hydrochloric acid were examined further; and preliminary tests of sludge seeding, hydrogen peroxide, ammonium hydroxide, and sodium hydroxide as scale control agents were conducted. In the course of this investigation, products from 49 different chemical companies were tested (see Table 8), and 23 other firms (see Table 9) were consulted regarding their chemicals for testing.

As a final comment on this investigation it is worthwhile to recall that at the beginning of the study virtually no knowledge existed on the types of compounds that would interact with the silica in the geothermal brine. Stabilization of the colloidal silica under the severe conditions of high temperature, high ionic strength, and high fluid shear rates is well outside the sphere of the usual colloid theory and applications in water treatment. Thus to screen large numbers of substances rather rapidly, we designed the brine treatment test apparatus as a small-scale flash system and operated it from a sidestream connected to the production we11. Because this sidestream was not perfectly representative of the main stream, and because the well was not operated at full flow during all of the studies, the prevailing fluid chemistry was probably not always constant and precisely equal to that which would be encountered in a $5 \mathrm{MW}$ full-scale facility. We have, however, developed considerable knowledge on how brine chemistry and plant design affects scale deposition and the action of the additives, so transfer of this technology to larger facilities should present few difficulties. 
Table 8. Chemical companies whose products were tested in the scale-control study.

Air Products

Aldrich Chemical

Alkaril Chemicals

American Can

American Cyanamid

American Heochst

Armak Chemicals

Ashland-Sherex

Austral Erwin

J. T. Baker Chemical

BASF-Wyandotte

Betz Laboratories

Bio-Rad Laboratories

Calgon

Champion Chemicals

Ciba-Geigy

Continental Chemical

Cordova Chemical

Croda

Cyclo Chemicals

Dearborn Chemical

Dow Chemical

Dow Corning

Drew Chemical

DuPont
Dynapol

Far Best

B. F. Goodrich

W. R. Grace, Organic Chemicals Div. Hercules

ICI Americas

Jefferson Chemical (Texaco)

Miranol Chemical

Monsanto

Nalco Chemical

C-E Natco

PVO International

Shell Chemical

A. E. Staley

Rohm and Haas

Scher Chemicals

Southwest Specialty Chemicals

Swift Chemical

Thompson-Hayward

$3 \mathrm{M}$

Tomah Products

Tretolite Div., Petrolite

Union Carbide

Witco Chemical 
Table 9. Chemical companies contacted during scale control study whose products were not tested.

Alcolac

Arjay

Armstrong Chemical

Byk-Mallinckrodt

Carson Chemical

Chevron Chemical

Conoco Chemicals

Consos

Fibreboard Paper Products

GAF

Gulf $0 i 1$ Chemicals

Henke1

\section{Illino is Mínerals}

Magna

Milliken Chemical

National Starch \& Chemical

NL Baroid

Onyx Chemical

Pilot Chemical

Ryco

Vertac

Wen-Don Chemical

Zimmite 


\section{Acknowledgments}

Design, fabrication, and operation of the Scale Control Test System has been the responsibility of the following: E. Kelly of Kelly Welding Services; R. G. Grogan, F. R. McLain, and A. Echeverria of the LLL Mechanical Engineering Department; R. T. Hasbrouck, W. F. Gee, and N. Rector of the LLL Electronics Engineering Department; L. Allen of E.G.\&G., Inc.; and P. Gunning, J. R. Alexander, and V. Jackson of Westec Services, Inc. Helpful discussions of this work with D. J. Meier of the Midland Macromolecular Institute are gratefully acknowledged. We also especially thank the following persons for their cooperation and advice in the evaluation of their companies products:

) R. H. Warner and D. N. Perucca of Armak, D. N. Roark and L. L. Hilton of Cordova Chemical, and N. M. Weinshenker of Dynapol. 


\section{References}

1. J. E. Harrar, F. E. Locke, L. E. Lorensen, C. H. Otto, Jr., S. B. Deutscher, W. P. Frey, and R. Lim, On-Line Tests of Organic Additives for the Inhibition of the Precipitation of Silica from Hypersaline Geothermal Brine, Lawrence Livermore Laboratory Rept. UCID-18091 (1979).

2. J. E. Harrar, F. E. Locke, C. H. Otto., Jr., L. E. Lorensen, and W. P. Frey, On-Line Tests of Organic Additives for the Inhibition of the Precipitation of Silica from Hypersaline Geothermal Brine II. Tests of Nitrogen-Containing Compounds, Silanes, and Additional Ethoxylated Compounds, Lawrence Livermore Laboratory Rept. UCID-18195 (1979).

3. J. E. Harrar, F. E. Locke, C. H. Otto, Jr., L. E. Lorensen, W. P. Frey, and E. 0. Snel1, On-Line Tests of Organic Additives for the Inhibition of the Precipitation of Silica from Hypersaline Geothermal Brine III. Scaling Measurements and Tests of Other Methods of Brine Modification, Lawrence Livermore Laboratory Rept. UCID-18238 (1979).

4. J. E. Harrar, F. E. Locke, C. H. Otto, Jr., L. E. Lorensen, S. B. Deutscher, W. P. Frey, and R. Lim, "Field Tests of Organic Additives for the Control of Scale at the Salton Sea Geothermal Field, " in Trans. Geothermal Resources Council Meeting, Reno, 1979, (Geothermal Resources Council, Davis, CA, 1979), pp. 295-298.

5. J. E. Harrar, F. E. Locke, C. H. Otto, Jr., S. B. Deutscher, W. P. Frey, L. E. Lorensen, E. 0. Snell, R. Lim, R. W. Ryon, and R. Quong, Final Report on Tests of Proprietary Additives as Antiscalants for Hypersaline Geothermal Brine, Lawrence Livermore Laboratory Rept. UCID-18521 (1980).

6. J. H. Hil1, J. E. Harrar, C. H. Otto, Jr., S. B. Deutscher, H. E. Crampton, R. G. Grogan, and V. H. Hendricks, Apparatus and Techniques for the Study of Precipitation of Solids and Silica from Hypersaline Geothermal Brine, Lawrence Livermore Laboratory Rept. UCRL-52799 (1979).

7. 0. J. Vetter and D. A. Campbe11, "Carbonate Scale Inhibition in Republic's East Mesa Geothermal Operations," Trans. Geothermal Resources Council Meeting, Reno, 1979 (Geothermal Resources Council, Davis, CA, 1979), pp. $757-760$.

8. H. P. Rothbaum, B. H. Anderton, R. F. Harrison, A. G. Rohde, and A. Slatter, "Effect of Silica Polymerization and pH on Geothermal Scaling," Geothermics, in press.

9. R. D. Gless, Jr., D. J. Dawson, and R. E. Wingard, "Process for Preparing Polyvinylamine and Salts Thereof," U. S. Patent 4,018,826, Apr. 19, 1977.

10. Data sheet on Mirapol A-15, Miranol Chemical Company, Irvington, N. J. 
11. J. E. Harrar, C. H. Otto, Jr., S. B. Deutscher, R. W. Ryon, and G. E. Tardiff, Studies of Brine Chemistry, Precipitation of Solids, and Scale Formation at the Salton Sea Geothermal Field, Lawrence Livermore Laboratory Rept. UCRL-52640 (1979).

12. R. K. Iler, The Chemistry of Silica (J. Wiley, New York, 1979).

13. Reference 12, pp. 288-301, 327, 384-397, 411-412, 571-572, 657-659, $680-686$, and $702-709$.

14. D. H. Napper, Ind. Eng. Chem. Prod. Res. Develop., 9, 467 (1970).

15. R. H. Ottewil1, "Effect of Nonionic Surfactants on the Stability of Dispersions," in Nonionic Surfactants, M. J. Schick, Ed. (Marce1 Dekker, New York, 1966), Chapter 19.

16. Reference 12 , p. 385 .

17. Reference 12, pp. 186-189.

18. Reference 12 , pp. 702-709.

19. D. N. Roark, Cordova Chemical Company, personal communication, 1979.

20. F. E. Bailey, Jr., and J. V. Koleske, "Configuration and Hydrodynamic Properties of the Polyoxyethylene Chain in Solution," in Nonionic Surfactants, Vol. 1, M. J. Schick, Ed. (Marcel Dekker, New York, 1966), Chapter 23.

21. A. R. Reid, Hercules Company, personal communication, 1978.

22. J. Z. Grens and L. B. Owen, "Field Evaluation of Scale Control Methods: Acidification," in Trans. Geothermal Resources Council Meeting, San Diego, 1977 (Geothermal Resources Counci1, Davis, CA, 1977), pp. 119-121.

23. 0. J. Vetter, J. Pet. Technol., 28, 1402 (1976).

24. Reference 12, pp. 680-686.

25. Principles of Industrial Water Treatment (Drew Chemical Corporation, Boonton, New Jersey, 1978).

26. C. Senda, Japanese Patent 74,106,440, October, 1974; Chem. Abstr. 83, 31692v.

27. W. J. Dickson and F. W. Jenkins (to Petrolite Corporation), U.S. Patent $3,262,791$; Che. Abstr. 66, 20850t.

28. L. B. Owen, Precipitation of Amorphous Silica from High-Temperature Hypersaline Geothermal Brines, Lawrence Livermore Laboratory Rept. UCRL-51866 (1975). 
29. R. Quong, F. Schoepflin, N. D. Stout, G. E. Tardiff, and F. R. McLain, "Processing of Geothermal Brine Effluents for Injection," in Trans. Geothermal Resources Council Meeting, Hilo, 1978 (Geothermal Resources Council, Davis, CA, 1978), pp 551-554.

30. J. L. Featherstone, D. R. Powell, and R. H. Van Note, "Stabilization of Highly Saline Brines," paper presented at Tech. Conf. of Soc. of Petroleum Engineers, AIME, Las Vegas, 1979.

31. L. B. Owen, E. Raber, C. H. Otto, Jr., R. Netherton, R. Neurath, and L. Allen, An Assessment of the Injectability of Conditioned Brine Produced by a Reaction Clarification-Gravity Filtration System in Operation at the Salton Sea Geothermal Field, Southern California, Lawrence Livermore Laboratory Rept. UC1D-18488 (1979).

32. M. T. Szabo, Soc. Pet. Eng. J., 15, 323 (1975).

33. Geothermal Energy - Recent Developments, M. J. Collie, Ed. (Noyes Data Corporation, Park Ridge, N.J., 1978), p. 126.

34. V. K. LaMer and T. W. Hear 7y, Rev. Pure Appl. Chem., 13, 112 (1963).

35. Polysciences, Inc. (Warrington, PA) Cat. No. 1564; Reference 12, pp. $778-781$.

36. Reference 12 , pp. 59-60.

37. K. Longley, "Polymeric Cation ic Surfactants," in Cationic Surfactants, $E$. Jungermann, Ed. (Marcel Dekker, New York, 1969), Chapter 5.

38. G. B. Butler (to Calgon Corp.), U.S. Patent $3,288,770$;

Diallyldimethylammonium chloride polymer.

39. J. E. Harrar, L. E. Lorensen, C. H. Otto, Jr., S. B. Deutscher, and G. E. Tardiff, "Effects of Organic Additives on the Formation of Solids from Hypersaline Brine," in Trans. Geothermal Resources Council Meeting, Hilo, 1978 (Geothermal Resources Council, Davis, CA, 1978), pp. 259-262. 
This report was prepared as an account of work sponsored by the United States Government. Neit her the United States nor the United States Department of Energy, nor any of their employees, nor any of their contractors, subcont ractors, or their employees, makes any warranty, express or implied, or assumes any legal liability or responsibility for the accuracy, completeness or usefulness of any informa tion, ap parat us, product or process disclosed, or represents that its use would not infringe privately owned rights.

Reference to a company or product name does not imply approval or recommendation of the product by the University of California or the U.S. Department of Energy to the exclusion of others that may be suitable.

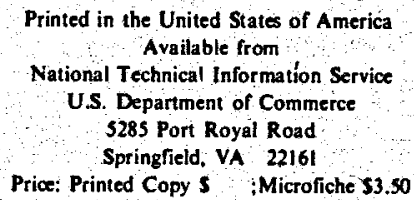

\begin{tabular}{|c|c|c|c|}
\hline Page Range & $\begin{array}{c}\text { Domestic } \\
\text { Price } \\
\end{array}$ & Page Range & $\begin{array}{r}\text { Domestic } \\
\text { Price } \\
\end{array}$ \\
\hline $001-025$ & S. 5.00 & $326-250$ & $\$ 18.00$ \\
\hline $026-050$ & 6.00 & $351-375$ & 19.00 \\
\hline $051-075$ & 7.00 & $376-400$ & 20.00 \\
\hline $076-100$ & 8.00 & $401-425$ & 21.00 \\
\hline $101-125$ & 9.00 & $426-450$ & 22.00 \\
\hline $126-150$ & 10.00 & $451-475$ & 23.00 \\
\hline $151-175$ & 11.00 & $476-500$ & 24.00 \\
\hline $176-200$ & 12.00 & $501-525$ & 25.00 \\
\hline $201-225$ & 13.00 & $526-550$ & 26.00 \\
\hline $\begin{array}{l}226-250 \\
251-275\end{array}$ & $\begin{array}{l}14.00 \\
15.00\end{array}$ & $\begin{array}{l}551-575 \\
576-600\end{array}$ & $\begin{array}{l}27.00 \\
28.00\end{array}$ \\
\hline 276-300 & 16.00 & 601 -up & \\
\hline $301-325$ & 17.00 & & \\
\hline
\end{tabular}

1 Add 2.00 for each additional 25 page horement from 601 pages up.

Work performed under the auspices of the U.S. Department of Energy by the Lawrence Livermore Laboratory under Contract W-7405-Eng-48. 


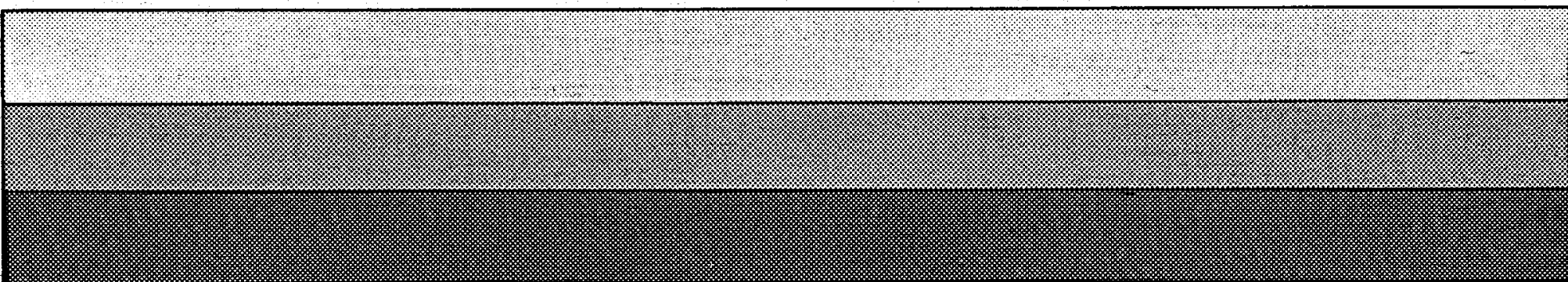

